\title{
Is there a value premium in cryptoasset markets?*
}

\author{
Luca J. Liebi ${ }^{\dagger}$
}

January 19, 2021

\begin{abstract}
This paper identifies active addresses-to-network value as an additional common risk factor in the returns on cryptoassets. Active addresses refer to the number of unique wallet addresses that conduct an on-chain transaction, whereas the network value of a cryptoasset corresponds to its market capitalization. Investigating 652 cryptoassets, I find that there are anomalous returns that increase with active addresses-to-network value ratio, a proxy for the value anomaly. Cryptoassets with a high active address to network value ratio yield on average 2.1 percentage points higher weekly returns compared to cryptoassets with low active addresses to network value ratio, and comparable size. A four-factor model directed at capturing the value pattern in average returns performs better than a three-factor model, including the market, size, and momentum factor. Importantly, the results suggest that cryptoasset prices are related to their fundamentals.
\end{abstract}

Keywords: cryptoasset, asset pricing model, active addresses-to-network value ratio, market $\beta$, size, momentum

JEL Classifications: G12

*I thank Alfredo Terrero, and Lucas Outumuro of IntoTheBlock for their help with data. I also thank Leah Homan of Coinmarketcap helping me with data from their website. Thanks also to Raffael Huber of Bitcoin Suisse for valuable suggestions. Last but not least, I am grateful for the helpful comments of Manuel Ammann, Zeno Adams, Tobias Hemauer, Stephan Heller, Alexander Cochardt, Mathis Mörke, Simon Straumann, Immanuel Lampe, Alexander Bechtel, Andrea Barbon, Tom Burdorf, Miriam Werner, Aristid Klumbies, Maximilian Schacker, Daniel Tinner, and Nicola Liebi.

${ }^{\dagger}$ University of St. Gallen, Swiss Institute of Banking and Finance, Unterer Graben 21, CH-9000 St. Gallen, Switzerland; Tel.: +41 71224 7015; E-mail address: luca.liebi@unisg.ch. 


\section{Introduction}

Cryptoasset markets have experienced a paradigm shift over the past decade: originally regarded as a speculative investment only, institutional investors increasingly appreciate cryptoassets' unique return drivers. As of 2020, $45 \%$ (27\%) of institutional investors in Europe (U.S.) already have exposure to cryptoassets, either directly or via future contracts.1 The novelty of cryptoassets, coupled with high past returns, and their low correlation to traditional asset classes make cryptoassets often regarded as an own asset class $2^{2}$ Despite considerable interest in this evolving asset class, the question of what factors drive expected returns of cryptoassets remains largely unexplored. This contrasts with the well-developed stock market literature that has tried over 316 potential anomalies to explain the crosssection of equity returns (Harvey and Liu (2016)). Considering the rapid advancement of cryptoassets, identifying cryptoasset specific measures that characterize the cross-section of average returns is an important task. Also, the development of an asset pricing model is of interest to academics in the finance and practitioners in the cryptoassets profession.

As yet, it is not clear what factors determine the expected return of cryptoassets. Cryptoassets represent a complex network of users interacting in the digital space. Theoretical models suggest that the fundamental value of cryptoassets positively depend on their network size. $3^{3}$ Cong et al. (2020) document that an increasing number of participants in the network brings about transactional benefits and leads to positive network externalities. Consequently, a larger user base increases cryptoasset prices and make the corresponding cryptoasset more attractive for other users and investors. In contrast, empirical studies show that non-fundamental factors affect cryptoasset prices.4 Since empirical asset pricing studies on cryptoassets are limited and often omit cryptoassets' fundamentals in their analysis, the validation of the above-mentioned theoretical model remains an open question.

This paper closes this gap and has two goals. The first is to examine the existence of a value premium in cryptoasset returns; that is, if cryptoassets with high ratios of active addresses to the network value (value cryptoassets) yield higher average returns than cryptoassets with low ratios of active addresses to the network value (growth cryptoassets). If so, the second goal is to test if a value factor has explanatory power for average cryptoasset returns in the cross-section.

\footnotetext{
${ }^{1}$ In the coming years, over $91 \%$ of all institutional investors surveyed by Fidelity (774 in total) are planning to invest in crypto assets (Fidelity Investments (2020))

${ }^{2}$ See Ankenbrand and Bieri (2018), Bianchi (2020), and Holovatiuk (2020)

${ }^{3}$ See Pagnotta and Buraschi (2018), Biais, Bisiere, Bouvard, Casamatta, and Menkveld (2018), and Cong, Li, and Wang (2020)

${ }^{4}$ See Makarov and Schoar (2020), and Griffin and Shams (2020)
} 
The first goal exclusively focuses on the value premium. I propose a value anomaly measure that is defined as the ratio between the average number of active addresses over the past 30 days to network value (aanv30). Active addresses refer to the number of unique wallet addresses that either sent or received an on-chain transaction over the course of the day. Active addresses do not equal active users in the network, as one unique user may own multiple active addresses 5 The network value of a cryptoasset equals its market capitalization. Alternative value anomaly measures include the average number of transactions over the past 30 days to network value, and average transaction value in USD to network value. Two methods are used to examine the value premium. First, all cryptoassets are sorted on the value anomaly into quintiles. When sorting on aanv30, I find an increasing pattern in average returns. The long-short portfolio, which is long in the highest level of aanv30 and short in the lowest level of aanv30, yields an average return of $1.6 \%$ per week. Unconditional bivariate sorts show that the value premium is most profound within small, low market $\beta$, low momentum, and high idiosyncratic volatility portfolios. Second, Fama and MacBeth (1973) regressions confirm the positive relation between aanv30 and future returns. My first result is easy to summarize. Value cryptoassets (characterized by high aanv30 ratios) yield higher returns than growth (characterized by low aanv30 ratios) cryptoassets.

The second aim of my papers centres around the value factor. Following the methodology of Fama and French (1993, 2012, 2015), and Liu, Liang, and Cui (2020), four cryptoasset specific common risk factors are constructed. I obtain excess market return (MKT), smallminus-big (SMB), momentum (WML), and high-minus-low (HML). The first three factors have previously been introduced by Liu et al. (2020). I propose the value (HML) factor as an additional common risk factor in the returns on cryptoassets. Figure 1 depicts cumulative weekly returns for all factors. The value (size) factor yields an average return of $2.1 \%$ (1.3\%) per week, and exhibits a Sharpe ratio of 0.33 (0.14). In a next step, the performance of the four-factor factor model to explain the common variation in cryptoasset returns is tested. Judged on regression intercepts, adding the value factor to the three-factor model of Liu et al. (2020) significantly improves the models ability to describe average cryptoasset returns. Moreover, spanning regressions indicate that with the addition of the value factor to the three-factor model, the MKT and SMB factor become redundant.

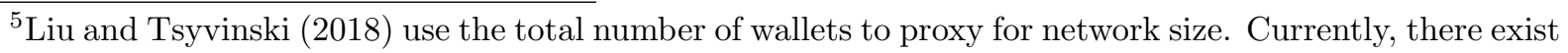
over 739 million bitcoin wallets. However, 707 million bitcoin wallets have no bitcoins stored, respectively are zero balance addresses. Moreover, only 1 million bitcoin wallets have been active on September $29^{t h}$, 2020. I argue that active addresses are a better proxy for network size as it specifically captures network utilization.
} 


\section{Figure 1. Cumulative factor returns}

This figure depicts cumulative weekly returns of the market (MKT), small-minus-big (SMB), momentum (WML), and high-minus-low (HML) factor; 04-July-2017 to 06-October-2020, 170 weeks. Returns are standardised to 100 for 04-July-2017. The y-axis is logarithmic.

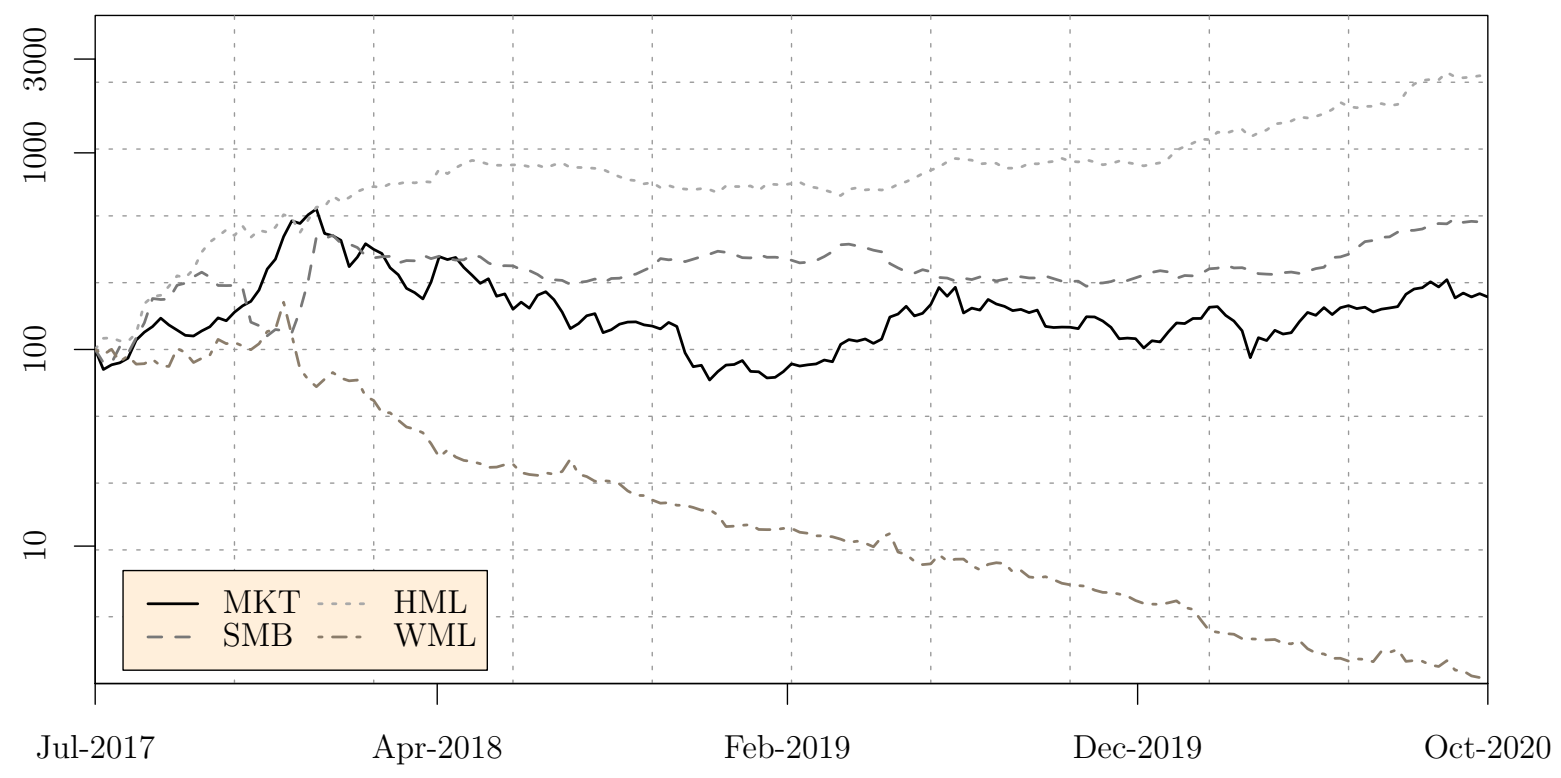

More broadly, this paper contributes to the ongoing debate on whether cryptoasset's prices are related to their fundamentals. On the one hand, Cheah and Fry (2015) argue that Bitcoin has a fundamental value of zero and contains a significant speculative component. Nobel laureate Robert Shiller interprets the cryptocurrency market as the prime example of a bubble $\sqrt{6}$ On the other hand, Biais et al. (2018) and Pagnotta and Buraschi (2018) emphazize that the fundamental value of cryptoassets depends on the number of users, which determines the magnitude of network externalities. Using a unique dataset, I am able to empirically test the theoretical models and shed light on the open question if fundamentals drive cryptoasset prices. To the best of my knowledge, this paper is the first to include the active addresses-to-network value ratio in traditional asset pricing tests inspired by Fama and French (1993, 2012, 2015). Importantly, the findings suggest that cryptoasset prices are related to their underlying blockchain fundamentals which has significant implications for the understanding of cryptoassets. Notably, I provide evidence against long-run irrational bubbles in the cryptoasset market, that occur when investors are solely driven by psychological factors unrelated to underlying fundamentals (Weber (2016), Dale, Johnson, and Tang (2005)).

\footnotetext{
[6yedele $(2017)$
} 
The paper is structured as follows. Section III provides a taxonomy for cryptoassets. Section III reviews the literature. Section IV presents the data and defines the anomaly variables. Section $V$ reports average returns from univariate, bivariate portfolio sorts, and cross-sectional regressions on the anomaly variables. Section VI defines the common risk factors and tests the factors using time-series regressions. Section VII provides robustness checks using daily data. Section VIII concludes. 


\section{Taxonomy of Cryptoassets}

Figure 2 categorises digital assets according to the Swiss Financial Market Supervisory Authority (FINMA (2018)). Digital assets can be subdivided into two categories: security tokens, and cryptoassets. Holders of security tokens are entitled to obtain dividends or interest payments. Thus, security tokens have comparable characteristics as traditional financial instruments, whose prices are determined by the present value of dividends or cash flows. In the U.S., a digital asset is legally classified by the Securities and Exchange Commission (SEC) as a security token if the asset passes the Howey Test.7 This is, if the asset mets all of the following four requirements (I) investment of money; (II) efforts of others; (III) expectation of profits, and (IV) money is invested in a common enterprise (Henderson and Raskin (2019)). In my empirical analysis, I solely focus on cryptoassets in the narrow sense (payment tokens, and utility tokens), which do not entitle the holder to earn any financial streams. Payment tokens are often referred to as cryptocurrencies and adopt a decentralized peer-to-peer network approach to enable users to make online payments without going through a financial intermediary. All transactions are chronologically recorded on the blockchain. Differences among cryptocurrencies arise from the underlying codebase, which specifies the consensus mechanism, the time until a new block is added to the blockchain (i.e. block time), and its hashing algorithm (see Härdle, Harvey, and Reule (2020) for a review on cryptocurrencies).

\section{Figure 2. Classification of digital assets}

This figure classifies digital asset types according to FINMA (2018). Cryptoassets in the narrow sense only include payment tokens (cryptocurrencies), and utility tokens. Security tokens entitle the holder to receive financial streams. In my analysis, I exclusively focus on cryptoassets in the narrow sense (payment tokens, and utility tokens). A similar definition is used by Blandin et al. (2019).

\begin{tabular}{|c|c|c|}
\hline Payment tokens & Utility tokens & Asset tokens \\
\hline $\begin{array}{l}\text { are synonymous with cryptocurrencies } \\
\text { and have no further functions or links } \\
\text { to other development projects. Tokens } \\
\text { may in some cases only develop the } \\
\text { necessary functionality and become } \\
\text { accepted as a means of payment } \\
\text { over a period of time. }\end{array}$ & $\begin{array}{l}\text { are tokens which are intended to } \\
\text { provide digital access to an } \\
\text { application or service. Thus, utility } \\
\text { tokens are not only used as a } \\
\text { means of exchange. Holding } \\
\text { utility tokens brings benefits such } \\
\text { as using the functionality that the } \\
\text { network provides. }\end{array}$ & $\begin{array}{l}\text { represent assets such as participations in } \\
\text { real physical underlyings, companies, } \\
\text { or earnings streams, or an entitlement to } \\
\text { dividends or interest payments. } \\
\text { In terms of their economic function, the } \\
\text { tokens are analogous to equities, } \\
\text { bonds or derivatives. }\end{array}$ \\
\hline e.g. Bitcoin, Litecoin & e.g. Golem, Filecoin & e.g. Crowdlitoken \\
\hline
\end{tabular}

${ }^{7}$ see Blandin, Cloots, Hussain, Rauchs, Saleuddin, Allen, Zhang, and Cloud (2019) for a global comparative study of cryptoasset regulation. 
Utility tokens typically require a blockchain infrastructure to operate, which in many cases is the Ethereum blockchain. In addition to the function as means of exchange, utility tokens provide the holder access to an application. An example is Golem, which allows the user to buy (or sell) computing power from a decentralized network. Filecoin enables clients to store their data on hardware provided by miners.

\section{Literature Review}

For stock markets, the academic literature has extensively studied the cross-section of returns. The Capital Asset Pricing Model (CAPM) was introduced by Sharpe (1964) and Lintner (1965), postulating a positive linear relationship between market risk and expected stock returns. However, academic research has provided strong evidence that the CAPM is misspecified as several anomalies were detected (e.g. size (Banz (1981)), value (Basu (1977, 1983)), and momentum (Jegadeesh and Titman (1993, 2001))). The list of potential anomalies to explain the cross-section of stock returns has grown to a factor zoo of over 316 variables (Harvey and Liu (2016)).

The value premium is well-documented in U.S. stock returns, which is, that average stock returns positively depend on the firm's book-to-market ratio (Fama and French (1992)). Similarly, Fama and French (2017) investigate the value premium internationally and report a value premium of $0.32 \%(0.20 \%)$ per month for Europe (North America). The three-factor model of Fama and French (1993) combines the value factor with size and the traditional excess market return factor of the CAPM. Carhart (1997) introduces the momentum factor, and Fama and French (2015) propose the profitability and investment factors to explain the cross-section of expected stock returns. Despite empirical parallels between cryptoasset and stock returns, cryptoassets fundamentally differ from traditional financial instruments, whose prices are determined by the present value of dividends or cash flows (Miller and Modigliani (1961), Campbell and Shiller (1988)) $!^{8}$ As described in Section II holders of cryptoassets are not entitled to earn financial streams.

Due to the above-mentioned structural difference between crptoassets and stocks, it is not surprising that the five-factor model of Fama and French $(2015)$ is unable to explain the cross-section of cryptoasset returns. Gregoriou (2019) regresses daily returns of ten cryptocurrencies on the Fama and French (2015) five-factor model, obtaining significant alphas

${ }^{8}$ empirical parallels include heteroscedasticity (Gkillas and Katsiampa $(2018)$ ), leptokurtosis (Chan, Chu, Nadarajah, and Osterrieder (2017)), and long-memory (Phillip, Chan, and Peiris (2019)) 
for all cryptocurrencies. Similarly, Liu and Tsyvinski (2018) document that cryptocurrencies have no exposure to the most common stock market and macroeconomic factors. Corbet, Lucey, Urquhart, and Yarovaya (2019) show that cryptocurrencies are isolated from financial and economic assets. Their findings point to the difficulty of constructing cryptocurrency factors based on information from other asset classes. Sovbetov (2018) investigates the five most prominent cryptocurrencies and shows that prices are related to cryptomarket-related factors such as market $\beta$. Li and Yi (2019) extend the sample to 893 cryptoassets, and provide suggestive evidence towards a factor structure in cryptoasset markets. Analogously to equity markets, small cryptocurrencies yield higher average returns than large cryptocurrencies (Li, Zhang, Xiong, and Wang (2020)). Kozlowski, Puleo, and Zhou (2020) provide evidence of a reversal effect in cryptocurrency markets. The authors show that past losers outperform past winners in the consecutive week by more than $10 \%$ per week. Zhang and Li (2020) show that idiosyncratic volatility is positively related to the expected return of cryptocurrencies. In a paper closely related to mine, Liu et al. (2020) identify market $\beta$, small-minus-big (SMB), and momentum (WML) as common risk factors in cryptocurrency markets. Combined, the three factors explain the variation in cryptocurrency returns.

Only a few empirical studies include cryptoasset fundamentals in their analysis. Liu and Tsyvinski (2018) test a cryptocurrency specific price-to-dividend ratio. Dividends are proxied by the number of bitcoin wallet users, measuring the fundamental value of bitcoin. The authors document a weak relationship between the price-to-dividend ratio and future bitcoin returns. Wang and Vergne (2017) include media attention and technological development to explain the cross-section of cryptocurrency returns. Technological developement is measured by eight indicators (e.g. the number of collaborators that contribute to the codebase) and is positively related to weekly returns. Bhambhwani, Delikouras, and Korniotis (2019) show that the intrinsic value of cryptocurrencies is determined by computing power and the network adoption rate. The latter is proxied by the number of unique addresses transacting on the blockchain. Cong et al. (2020) develop a dynamic model to show the feedback effect between user adoption, token utility, and token price. Thereby, a larger user base positively affects token utility due to network externalities. When today's users expect more users to join the network in the future, investors anticipate an increasing future token demand and leads to price appreciation. These findings contrast to Cheah and Fry (2015), who show that investor sentiment drives Bitcoin returns. Similarly, Corbet, Lucey, and Yarovaya (2018) detect several periods of pricing bubbles in Bitcoin and Ethereum. 


\section{Data and Variables}

This Section describes the data sources, outlines the variable construction, and provides the sample descriptive statistics. The online Appendix provides supplementary details including a list of all cryptoassets.

\section{A. Data on Cryptoassets}

First, daily cryptoasset data are obtained from Coinmarketcap. Coinmarketcap is one of the leading sources for financial cryptoasset information, providing historical data from 2013 onwards. The data includes open, high, low, closing prices, trading volume, and market capitalization. Coinmarketcap lists assets that are classified as a cryptoasset, have an operational website, and are actively traded on at least one public exchange. Since cryptoasset prices differ across exchanges (Makarov and Schoar (2020)), Coinmarketcap reports volume-weighted prices across all exchanges and cryptoasset pairs.99 Many previous studies on cryptoassets have used the same primary data source (e.g. Liu et al. (2020), Gkillas and Katsiampa (2018), and $\mathrm{Hu}$, Parlour, and Rajan (2019)). One drawback of Coinmarketcap is that the official website only displays data on currently listed cryptoassets. Thus, information on delisted cryptoassets must be downloaded by accessing historical snapshots of the webpage. The crypto2 package by Vent and Stoeckl (2019) addresses the survivorship bias.10 The package accesses a historical snapshot of the webpage at the end of each month and downloads historical data of delisted as well as listed coins.

The sample excludes stablecoins that mimic fiat currencies' price (e.g. Gemini Dollar, Binance USD, Tether, TrueUSD, and CryptoFranc). Most fiat stablecoins are collateralized, meaning that they are backed by fiat the corresponding fiat currency with a 1:1 ratio. Some stablecoins also track commodity prices (e.g. Tether Gold). In a similar manner, these commodity stablecoins are removed from the sample. Additionally, all cryptoassets with no reported trading volume or market capitalization are omitted, resulting in a sample of 2087 cryptoassets. The market return is given by the value-weighted return of all 2087 cryptoassets. Even though a large universe of cryptoassets exists, the market is highly concentrated around a few cryptocurrencies. Combined, Bitcoin and Ether account for $68 \%$ of total market capitalization, which resembles in a correlation of 0.94 between Bitcoin and the market returns. The risk-free rate is defined by the one-month U.S. Treasury bill rate obtained from the official Fama French Website.

${ }^{9}$ CoinMarketCap $(2020)$

${ }^{10}$ Kaiser and Stöckl 2020) use this R package to account for the survivorship bias. 
Second, I acquire cryptoasset fundamentals of 635 assets from IntoTheBlock. IntoTheBlock runs nodes on most blockchains and extracts blockchain fundamentals. Fundamentals include active addresses, number of new addresses, total number of addresses, zero balance addresses, number of transactions, and daily transaction volume in USD. As a secondary source for blockchain fundamentals, I use data from Coinmetrics for 20 cryptoassets which are not available on IntoTheBlock (e.g. Bitcoin Gold, Grin, and Maid). Importantly, Monero (XMR), Ripple (XRP), and Stellar (XLM) are excluded from my sample. Unlike Bitcoin, Monero aims at making transactions truly anonymous. It does so by masking a single transaction across multiple addresses. This systematically increases the number of active address count, transaction volume, and the number of transactions (Narayanan, Bonneau, Felten, Miller, and Goldfeder (2016)). Ripple is accused by the SEC to have raised over $\$ 1.3$ billion in an unregistered securities offering, which classifies Ripple as a security token and not as cryptoassets 11 Similarly, Stellar is potential candidate of a security token. From all cryptocurrencies rated by the Crypto Rating Countil (CRC), Stellar exhibits the second-highest (after Ripple) probability of being classified as a security token by the SEC The final sample includes 652 cryptoassets.

Finally, I merge the financial data from Coinmarketcap with the cryptoasset fundamentals. If financial data is not available on Coinmarketcap, I use Coingecko as a secondary data source. I set a minimum threshold at 50 cryptoassets that must be included in the sample. This threshold is first met on July $4^{\text {th }}, 2017$. Thus, the sample period is from July $4^{\text {th }}, 2017$ to October $6^{t h}, 2020$. This equals 1190 total trading days, respectively 170 weeks. At the beginning (end) of the period, the sample includes 50 (638) cryptoassets. I provide a list of all cryptoassets and sample data in the online Appendix.

\section{B. Variable Construction}

In my main analysis, I focus on the cross-section of weekly cryptoasset returns. I construct weekly returns and anomaly variables from daily data for each cryptoasset on a rollingwindow scheme. Table I defines the anomaly variables. Overall, I construct 11 cryptoasset specific anomaly variables to forecast 1 -week ahead returns. I measure weekly returns from Tuesday's close price to Tuesday in the consecutive week, following Liu et al. (2020).

The first anomaly variable equals the market $\beta$, which is the slope coefficient when regressing excess returns of a cryptoasset on the excess market return. The market $\beta$ is

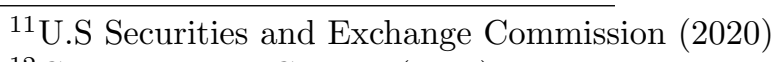

12 Crypto Rating Council 2020 


\section{Table I Variable description}

This table provides an overview of the dependant variable and all anomaly variables of interest. The table includes notation, category of the anomaly variable, and the corresponding definition.

\begin{tabular}{|c|c|c|c|}
\hline Variable & Notation & Category & Definition \\
\hline \multicolumn{4}{|l|}{ Dependent Variable } \\
\hline Excess weekly return & $r_{i}$ & - & $\begin{array}{l}\text { Weekly returns are measured from Tuesday's } \\
\text { closing price at time t until Tuesday in the } \\
\text { following week at time t+1. The excess re- } \\
\text { turn is defined as the weekly return minus the } \\
\text { weekly risk-free rate (one-month U.S. Treasury } \\
\text { bill rate). }\end{array}$ \\
\hline
\end{tabular}

\section{Anomaly variables}

Market beta

$\beta_{M K T} \quad$ Volatility

$\begin{array}{lll}\text { Size } & \text { size } & \text { Size } \\ \text { Momentum } & \text { mom } & \text { Momentum } \\ \text { Idiosyncratic volatility } & \text { ivol } & \text { Volatility }\end{array}$

Amihud's illiquidity measure

Transaction volume in $\$$ to network value

30 days moving average of transaction volume in $\$$ to network value

Number of transactions to network value

30 days moving average of daily transactions to network value

Number of active addresses to network value

30 days moving average of the number of active addresses to network value

\section{amihud Liquidity}

tvnv Value

tvnv30 Value

txnv Value

txnv30 Value

aanv Value

aanv30 Value
Slope coefficient in the excess returns of cryptocurrencies on the excess market return from t-28 days until t. I chose an estimation window of four weeks (28 days) according to Zhang and $\mathrm{Li}(2020)$. The market return is defined as value-weighted return of the 2087 cryptoassets. The risk-free rate is defined by the one-month U.S. Treasury bill rate.

Natural logarithm of the market capitalisation at the portfolio formation day $(=\mathrm{t})$.

Cumulative return over the past 90 days from t-90 until portfolio formation day $t$.

Standard deviation of the residuals after estimating the following regression using weekly returns over 28 days before portfolio formation. $r_{i, t}-r_{f}=\alpha+\beta_{M K T}\left(r_{M K T, t}-r_{f}\right)+\epsilon_{i}$ The average absolute daily return divided by dollar volume in the portfolio formation week. Transaction volume in $\$$ divided by the network value (= market capitalization) at time t.

Average daily transaction volume in $\$$ over the past 30 days divided by the network value at time t.

The number of daily transactions divided by the network value at time $t$.

Average number of daily transactions over the past 30 days divided by the network value at time t.

Number of active addresses to network value at time t.

Average number of active addresses over the past 30 days divided by the network value at time t.

On-chain volume transferred in $\$$ at time t. Number of on-chain transactions at time $t$. Number of unique addresses that either sent or received a ledger change over the course of the day. Notice that a single user can have multiple addresses. The number of active addresses represents an upper bound for unique daily users.

estimated on a rolling-window scheme with a window length of 28 days (Zhang and Li (2020)). Size is the natural logarithm of the market capitalization at time t. Momentum equals the cumulative return in cryptoasset returns from t-90 days to t (Grobys and Sapkota (2019)), and idiosyncratic volatility equals the standard deviation of the residuals after estimating 
the CAPM. Amihud's illiquidity measure is defined as the absolute weekly return divided by the weekly trading volume in USD (Amihud (2002)).

Besides, I introduce six potential value anomalies. The active addresses-to-network value (aanv) ratio is defined by the number of unique active addresses of a cryptoasset divided by its network value. An active address is an address that either sent or received a ledger change over the course of the day. Thus, when Anna makes an on-chain transaction to Bob, two unique addresses are active. These transactions are recorded and reflected on the public ledger. Active addresses in a network do not equal the number of active users, but it represents an upper bound. Importantly, active addresses are an on-chain measure and are not related to the trading volume on exchanges. Intra-exchange trades occur off-chain and are not recorded on the public ledger. Only when a user moves cryptoassets into an exchange from the outside, active addresses increase. ${ }^{13}$ The network value of a cryptoasset represents its market capitalization.

Analogously, I define the number of on-chain transactions-to-network value (txnv) ratio, and on-chain transaction volume in USD-to-network value (tvnv) ratio. ${ }^{14}$ All three value anomaly ratios are highly sensitive to cryptocurrency mixers (tumblers). Mixers try to solve the pseudonymous problem of cryptocurrencies. For Bitcoin it is possible to link wallets to real-world identities. As the name suggests, mixers "mix" cryptocurrencies from several users through multiple addresses. This positively affects active addresses, number of transactions, and transaction volume. Figure 3 depicts the effect of an Ethereum mixer on daily transaction volume, and active addresses. Total daily transaction volume reached its peak in January $14^{\text {th }}, 2018$ with a daily transaction volume of $\$ 34$ billion. Coinmetrics estimates an adjusted transaction volume of $\$ 8.3$ billion. Hence, crypto mixers account for more than $70 \%$ of all ETH transactions. Moreover, a downside of the tvnv ratio are large on-chain transactions. On August $6^{\text {th }}, 2020$ a single transaction of $\$ 8.9$ billion was recorded on the bitcoin blockchain 15 Such large transactions positively affect the tvnv ratio.

\footnotetext{
${ }^{13}$ Chainanalysis (2019) compares on-chain transactions to the off-chain trading volumes on exchanges to detect fake trading volume.

${ }^{14} \mathrm{Woo}(2017)$ introduced the network value-to-transactions ratio to detect cryptocurrency bubbles. I define the txnv ratio as the inverse of the network value-to-transactions ratio.

$\sqrt[15]{\text { Erazo }(2020)}$
} 
Figure 3. The effect of the Ethereum mixer

This figure depicts the effect of the Ethereum (ETH) mixer on transaction volume, and the number of active addresses. The mixer was active twice: the first period was from November $22^{\text {nd }}$, 2016 till January $14^{\text {th }}$, 2017. Here the second period is depicted, lasting from February $13^{\text {th }}, 2017$ till February, $27^{t h}, 2018$. In the latter period, the mixer generated more than $70 \%$ of all ETH transfers in the network. I plot transaction volume in $\$\left(T V_{u n a d j}\right)$, adj. transaction volume $\left(T V_{\text {adj. }}\right)$, and on the second y-axis the number of active addresses (AA). Data stem from Coinmetrics.io.

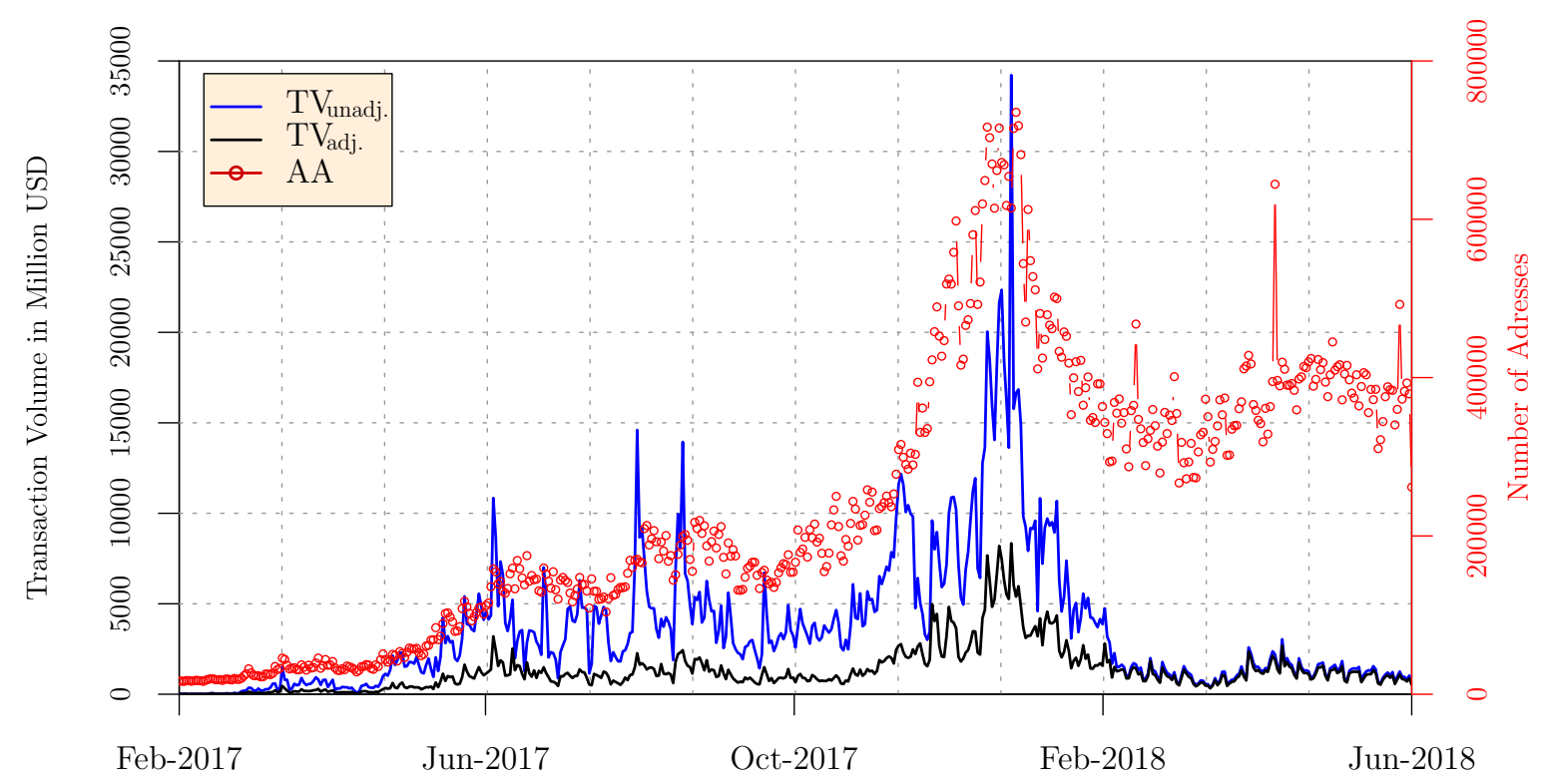

I account for cryptocurrency mixers and daily noise in the value anomylies by smoothing all value anomalies variables using the 30-days moving average in the numerator. My main analysis centers around the aanv30, which is defined according to equation 1. The remaining value anomalies (tvnv30, and txnv30) are defined accordingly.

$$
\text { aanv30 } 0_{i, t}=\frac{\frac{1}{30} \sum_{s=0}^{29} \text { number of active addresses }_{i, t-s}}{\text { network value } i, t}
$$

Figure 4 reports average and median aanv30 ratios from July $4^{\text {th }}$, 2017 to October $6^{\text {th }}$, 2020. The average aanv30 ratio peaks on September $11^{\text {th }}, 2017$ with a standard deviation of $0.0057 \%$. The cross-sectional mean (median) aanv30 ratio over this period equals $0.00052 \%$ $(0.00051 \%)$. The median remains relatively stable over the investigated period, with a trend towards lower cross-sectional mean of aanv30 ratios for cryptoassets. The dashed lines represent the aanv30 ratios for Bitcoin (BTC) and Basic Attention Token (BAT). Following the introduction of Bitcoin futures, the aanv30 ratio of Bitcoin remains close to the crosssectional median. BAT's aanv30 ratio lies for a short time above the cross-sectional mean.

Table A1 presents summary statistics of weekly observations. All variables of interest 
Figure 4. Time-series of summary statistics for aanv30 ratios

Cross-sectional summary statistics (mean, and median) of average active addresses over the past 30 days to network value (aanv30) ratios for 652 cryptoassets; 04-July-2017 to 06-October-2020, 170 weeks. Mean (median) is depicted in solid blue (black) The goldenrod, dashed line represents the aanv30 ratio of bitcoin (BTC), and darkgrey equals the aanv30 ratio for Basic Attention Token (BAT). The first red vertical line represent the first trading day (December 10 ${ }^{t h}$, 2017) of Bitcoin Futures on the CBOE Futures Exchange. The second red dashed line remarks the Bitcoin Price Crash of $17 \%$ within one hour during the Coronavirus panic (March $\left.12^{t h}, 2020\right)$.

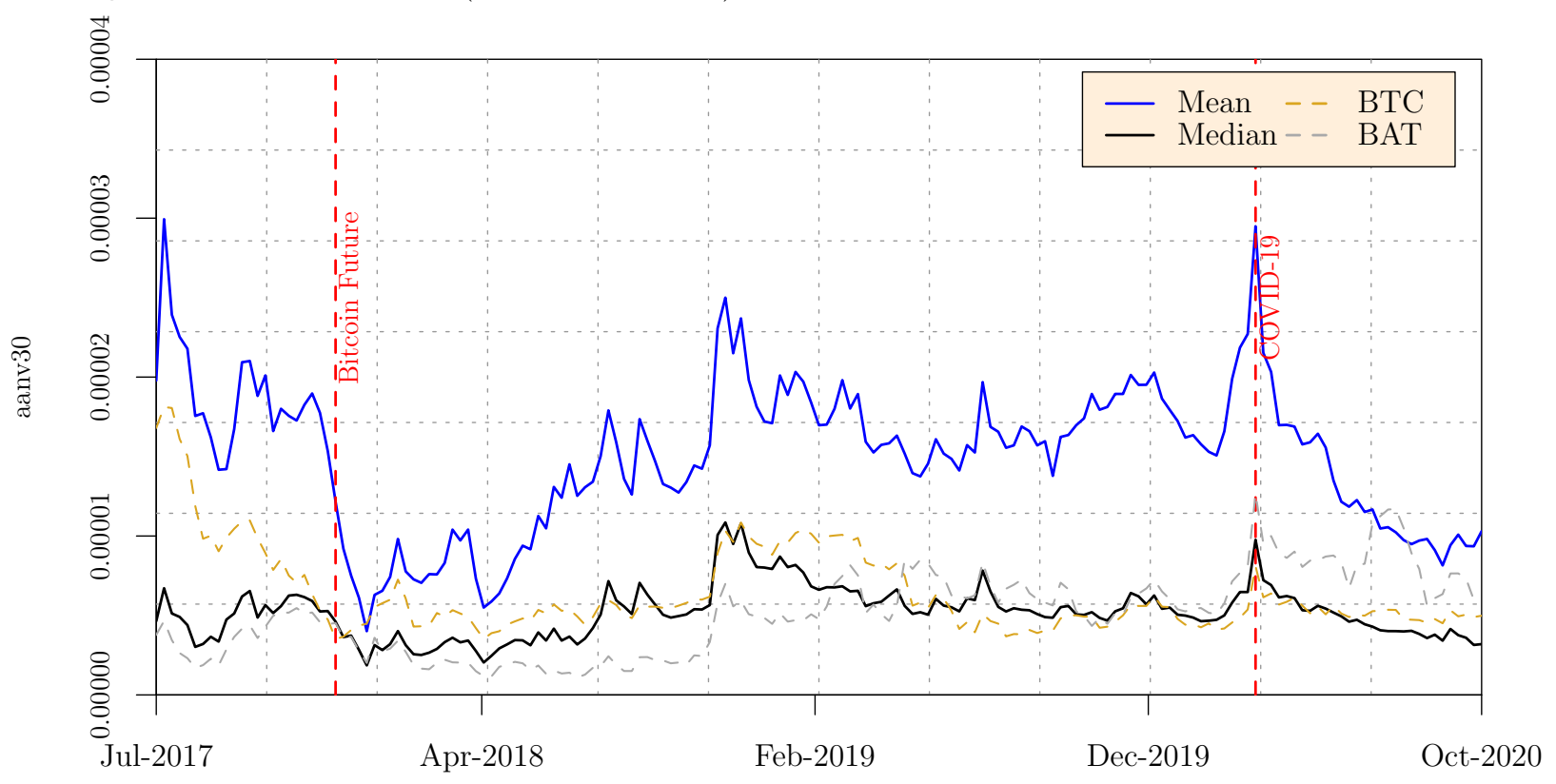

are winsorized at the $1 \%$ and $99 \%$ level. Table A2 depicts pearson (lower triangular) and spearman (upper triangular) correlation coefficients of the anomaly variables. As expected, the aanv30 ratio exhibits a high spearman correlation of 0.95 (0.4) to the txnv30 (tvnv30) ratio. Moreover, cryptoassets display considerable time-variation in the aanv30 ratio. Table A3 depicts the transition matrix for cryptoassets when sorted at the end of each Tuesday on aanv30 (txnv30, tvnv30) into quintiles. Interestingly, the probability for cryptoasset i with a aanv30 ratio in the lowest quntile exhibits a probability of remaining in the first (fifth) quintile of $20 \%(21 \%)$. 


\section{Cross-section of Expected Returns}

Section V.A reports weekly returns from univariate portfolio sorts. Section V.B studies the interaction between the value anomaly and already established risk factors. Section V.C presents the results of Fama and MacBeth (1973) regressions.

\section{A. Univariate Sorts}

At the end of each Tuesday, I rank cryptoassets into five groups based on the anomaly variable under investigation and calculate portfolio returns from Tuesday (t) until Tuesday in the consecutive week $(\mathrm{t}+1)$. Thus, the anomaly variables are lagged by one week to make sure the information is publicly available.

Table II reports value-weighted (Panel A) and equal-weighted (Panel B) weekly returns for quintile portfolios sorted on the market $\beta$, size, 90-days momentum, idiosyncratic volatility, amihud liquidity measure, and the six proposed value anomalies. Both types of weighted average returns show a decreasing pattern on size and momentum. Sorted for size, I document an average value-weighted (equal-weighted) return difference of $1.65 \%$; $\mathrm{t}=2.29(3.76 \%$; $\mathrm{t}=5.96$ ) between cryptoassets with the lowest, and cryptoassets with the highest level of size. Notice that the high-minus-low (HML) column in Table II reports average weekly returns of a long-short strategy that is long in the fifth and short in the first quintile portfolio 16 90-day momentum is associated with lower average returns in the consecutive week. Past winners earn on average $1.55 \%(\mathrm{t}=-1.57)$ lower returns than past losers for value-weighted portfolios and $4.51 \%(\mathrm{t}=-9.64)$ for equal-weighted portfolios. This result confirms the findings of Kozlowski et al. (2020), who find a significant return reversal effect in crytoasset markets. No significant relationship between market $\beta$ and average weekly returns is found. With respect to idiosyncratic volatility and amihud's liquidity measure the results are inconclusive, as the value-weighted (equal-weighted) HML return is negative (positive).

Importantly, I find anomalous returns that increase with the aanv30 ratio. The HML portfolio produces an average weekly return $1.62 \%(\mathrm{t}=2.18)$. Except for the third aanv30 quintile, value-weighted returns increase linearly across all portfolios. For equal-weighted portfolios, the long-short aanv30 strategy yields a mean return of $3.58 \%(t=7.72)$. Thus, the value premium is large in economic magnitude and statistically significant. The increasing pattern in average returns is also found when cryptoassets are sorted on tvnv30 and txnv30, respectively. Value anomalies that do not incorporate the moving average over the past 30 days in the numerator (e.g. aanv) result in a non-linearly increasing pattern in value-weighted weekly returns from the first to the fifth quintile portfolio.

\footnotetext{
${ }^{16}$ The HML size portfolio in Table II is long in big and short in small cryptoassets.
} 
Additionally, Table II shows portfolio returns adjusted for systematic risk. The alpha equals the intercept from regressing the HML portfolio returns on the cryptoasset market portfolio. The alpha of the HML aanv30 portfolio is $1.47 \%$ for value-weighted portfolios and $3.53 \%$ for equal-weighted portfolios. Similarly, the long-short txnv30 portfolio yields a value-weighted (equal-weighted) alpha of $1.38 \%$ (3.53\%). The results provide preliminary evidence that value cryptoassets have higher average returns than growth cryptoassets. This implies that the aanv30 ratio might be a reliable indicator of subsequent cryptoasset returns from a cross-sectional perspective. 


\section{Table II One-dimensional weekly sorts}

Averages of weekly percent excess returns for value-weighted (Panel A: VW) and equal-weighted (Panel B: EW) portfolios formed on market beta, size, 90-day momentum (mom), idiosyncratic volatility (ivol), amihud illiquidity measure (amihud), transaction volume in USD to network value (tvnv), number of transactions to network value (txnv), and active addresses to network value (adnv). For the latter three anomaly variables, I provide the results using the moving average over the past 30 days (t-30 days) in the nominator (e.g. tvnv30 - is the average transaction volume over the past 30 days divided by the network value at time $t$ ); $04-J u l y-2017$ to 06 -October-2020, 170 weeks. At the end of each Tuesday $(=\mathrm{t})$, crypotoassets are sorted into quintiles based on the corresponding anomaly variable. In the sort time $\mathrm{t}$, market beta is estimated from $t-28$ days until $t$, size is the market cap at time $t$, momentum is the cumulative return from t-90 days to $t$, idiosyncratic volatility is the standard deviation of the residuals after estimating the CAPM from $t-28$ days until $t$. Then, value-weighted and equal-weighted portfolio returns are calculated from $t$ to $t+1$. The high-minus-low (HML) column reports the average weekly returns of the 5-1 portfolio. The alpha $(\alpha)$ is the intercept obtained from a regression of HML returns on the market return. T-statistics are reported in parenthesis below the coefficients. $*, * *, * * *$ indicate statistical significance levels at the $10 \%, 5 \%, 1 \%$ levels, respectively.

\begin{tabular}{|c|c|c|c|c|c|c|c|c|c|c|c|c|c|c|c|}
\hline A: VW & Low & 2 & 3 & 4 & High & HML & $\alpha$ & B: EW & Low & 2 & 3 & 4 & High & HML & $\alpha$ \\
\hline market & $\begin{array}{l}0.65 \\
(0.63)\end{array}$ & $\begin{array}{l}0.29 \\
(0.32)\end{array}$ & $\begin{array}{l}1.45 \\
(1.41)\end{array}$ & $\begin{array}{l}0.24 \\
(0.23)\end{array}$ & $\begin{array}{l}-0.6 \\
(-0.52)\end{array}$ & $\begin{array}{l}-1.25 \\
(-1.29)\end{array}$ & $\begin{array}{l}-1.42 \\
(-1.48)\end{array}$ & market & $\begin{array}{l}1.41 \\
(1.42)\end{array}$ & $\begin{array}{l}0.76 \\
(0.74)\end{array}$ & $\begin{array}{l}1.39 \\
(1.32)\end{array}$ & $\begin{array}{l}0.96 \\
(0.92)\end{array}$ & $\begin{array}{l}1.27 \\
(1.19)\end{array}$ & $\begin{array}{l}-0.14 \\
(-0.30)\end{array}$ & $\begin{array}{l}-0.28 \\
(-0.61)\end{array}$ \\
\hline size & $\begin{array}{l}2.77 \\
(2.55)\end{array}$ & $\begin{array}{l}0.91 \\
(0.82)\end{array}$ & $\begin{array}{l}0.62 \\
(0.56)\end{array}$ & $\begin{array}{l}0.36 \\
(0.33)\end{array}$ & $\begin{array}{l}1.12 \\
(1.31)\end{array}$ & $\begin{array}{l}-1.65^{* *} \\
(-2.29)\end{array}$ & $\begin{array}{l}-1.64^{* *} \\
(-2.27)\end{array}$ & size & $\begin{array}{l}3.92 \\
(3.72)\end{array}$ & $\begin{array}{l}1.01 \\
(0.91)\end{array}$ & $\begin{array}{l}0.52 \\
(0.48)\end{array}$ & $\begin{array}{l}0.47 \\
(0.44)\end{array}$ & $\begin{array}{l}0.16 \\
(0.16)\end{array}$ & $\begin{array}{l}-3.76^{* * *} \\
(-5.96)\end{array}$ & $\begin{array}{l}-3.78^{* * *} \\
(-5.95)\end{array}$ \\
\hline mom & $\begin{array}{l}2.01 \\
(1.71)\end{array}$ & $\begin{array}{l}0.85 \\
(0.74)\end{array}$ & $\begin{array}{l}1.42 \\
(1.30)\end{array}$ & $\begin{array}{l}0.54 \\
(0.54)\end{array}$ & $\begin{array}{l}0.91 \\
(0.95)\end{array}$ & $\begin{array}{l}-1.55 \\
(-1.57)\end{array}$ & $\begin{array}{l}-1.51 \\
(-1.51)\end{array}$ & mom & $\begin{array}{l}3.78 \\
(3.56)\end{array}$ & $\begin{array}{l}1.19 \\
(1.15)\end{array}$ & $\begin{array}{l}0.68 \\
(0.68)\end{array}$ & $\begin{array}{l}0.4 \\
(0.40)\end{array}$ & $\begin{array}{l}-0.3 \\
(-0.31)\end{array}$ & $\begin{array}{l}-4.52^{* * *} \\
(-9.76)\end{array}$ & $\begin{array}{l}-4.51 * * * \\
(-9.64)\end{array}$ \\
\hline ivol & $\begin{array}{l}1.14 \\
(1.34)\end{array}$ & $\begin{array}{l}0.77 \\
(0.67)\end{array}$ & $\begin{array}{l}0.38 \\
(0.30)\end{array}$ & $\begin{array}{l}-0.91 \\
(-0.76)\end{array}$ & $\begin{array}{l}-2.1 \\
(-1.51)\end{array}$ & $\begin{array}{l}-3.25^{* *} \\
(-2.44)\end{array}$ & $\begin{array}{l}-2.94^{* *} \\
(-2.24)\end{array}$ & ivol & $\begin{array}{l}0.87 \\
(0.87)\end{array}$ & $\begin{array}{l}0.98 \\
(0.94)\end{array}$ & $\begin{array}{l}0.89 \\
(0.84)\end{array}$ & $\begin{array}{l}1.16 \\
(1.09)\end{array}$ & $\begin{array}{l}1.89 \\
(1.83)\end{array}$ & $\begin{array}{l}1.03^{*} \\
(1.78)\end{array}$ & $\begin{array}{l}1.07^{*} \\
(1.84)\end{array}$ \\
\hline amihud & $\begin{array}{l}1.14 \\
(1.34)\end{array}$ & $\begin{array}{l}0.17 \\
(0.16)\end{array}$ & $\begin{array}{l}-0.19 \\
(-0.18)\end{array}$ & $\begin{array}{l}0.01 \\
(0.01)\end{array}$ & $\begin{array}{l}-0.7 \\
(-0.60)\end{array}$ & $\begin{array}{l}-1.84^{* *} \\
(-2.18)\end{array}$ & $\begin{array}{l}-1.83^{* *} \\
(-2.15)\end{array}$ & amihud & $\begin{array}{l}0.59 \\
(0.58)\end{array}$ & $\begin{array}{l}0.72 \\
(0.66)\end{array}$ & $\begin{array}{l}0.78 \\
(0.72)\end{array}$ & $\begin{array}{l}0.83 \\
(0.77)\end{array}$ & $\begin{array}{l}2.82 \\
(2.70)\end{array}$ & $\begin{array}{l}2.23^{* * *} \\
(3.79)\end{array}$ & $\begin{array}{l}2.28^{* * *} \\
(3.84)\end{array}$ \\
\hline tvnv & $\begin{array}{l}0.39 \\
(0.31)\end{array}$ & $\begin{array}{l}-0.82 \\
(-0.88)\end{array}$ & $\begin{array}{l}0.53 \\
(0.50)\end{array}$ & $\begin{array}{l}1.12 \\
(1.03)\end{array}$ & $\begin{array}{l}1.13 \\
(1.33)\end{array}$ & $\begin{array}{l}0.74 \\
(0.79)\end{array}$ & $\begin{array}{l}0.81 \\
(0.85)\end{array}$ & tvnv & $\begin{array}{l}1.71 \\
(1.64)\end{array}$ & $\begin{array}{l}0.79 \\
(0.78)\end{array}$ & $\begin{array}{l}1.2 \\
(1.11)\end{array}$ & $\begin{array}{l}1.1 \\
(1.01)\end{array}$ & $\begin{array}{l}0.88 \\
(0.82)\end{array}$ & $\begin{array}{c}-0.83^{*} \\
(-1.89)\end{array}$ & $\begin{array}{l}-0.89 * * \\
(-2.03)\end{array}$ \\
\hline tvnv30 & $\begin{array}{l}-0.2 \\
(-0.18)\end{array}$ & $\begin{array}{l}-0.57 \\
(-0.58)\end{array}$ & $\begin{array}{l}0.17 \\
(0.17)\end{array}$ & $\begin{array}{l}0.3 \\
(0.30)\end{array}$ & $\begin{array}{l}1.24 \\
(1.45)\end{array}$ & $\begin{array}{l}1.44 \\
(1.64)\end{array}$ & $\begin{array}{l}1.43 \\
(1.62)\end{array}$ & tvnv30 & $\begin{array}{l}0.83 \\
(0.86)\end{array}$ & $\begin{array}{l}0.75 \\
(0.75)\end{array}$ & $\begin{array}{l}1.54 \\
(1.45)\end{array}$ & $\begin{array}{l}1.02 \\
(0.96)\end{array}$ & $\begin{array}{l}1.37 \\
(1.29)\end{array}$ & $\begin{array}{l}0.54 \\
(1.34)\end{array}$ & $\begin{array}{l}0.43 \\
(1.10)\end{array}$ \\
\hline txnv & $\begin{array}{l}-0.28 \\
(-0.25)\end{array}$ & $\begin{array}{l}0.83 \\
(0.87)\end{array}$ & $\begin{array}{l}1.15 \\
(1.06)\end{array}$ & $\begin{array}{l}0.6 \\
(0.57)\end{array}$ & $\begin{array}{l}0.67 \\
(0.62)\end{array}$ & $\begin{array}{l}0.95 \\
(1.05)\end{array}$ & $\begin{array}{l}0.76 \\
(0.84)\end{array}$ & txnv & $\begin{array}{l}1.01 \\
(1.05)\end{array}$ & $\begin{array}{l}0.42 \\
(0.41)\end{array}$ & $\begin{array}{l}0.89 \\
(0.82)\end{array}$ & $\begin{array}{l}1.25 \\
(1.10)\end{array}$ & $\begin{array}{l}2.13 \\
(1.96)\end{array}$ & $\begin{array}{l}1.12^{* * *} \\
(2.66)\end{array}$ & $\begin{array}{l}1.09 * * \\
(2.57)\end{array}$ \\
\hline txnv30 & $\begin{array}{l}-0.53 \\
(-0.61)\end{array}$ & $\begin{array}{l}1.26 \\
(1.40)\end{array}$ & $\begin{array}{l}0.66 \\
(0.57)\end{array}$ & $\begin{array}{l}0.54 \\
(0.50)\end{array}$ & $\begin{array}{l}1.14 \\
(1.01)\end{array}$ & $\begin{array}{l}1.67^{* *} \\
(2.28)\end{array}$ & $\begin{array}{l}1.38^{* *} \\
(1.99)\end{array}$ & txnv30 & $\begin{array}{l}-0.37 \\
(-0.41)\end{array}$ & $\begin{array}{l}0.68 \\
(0.67)\end{array}$ & $\begin{array}{l}0.79 \\
(0.74)\end{array}$ & $\begin{array}{l}1.49 \\
(1.35)\end{array}$ & $\begin{array}{l}3 \\
(2.82)\end{array}$ & $\begin{array}{l}3.37^{* * *} \\
(7.63)\end{array}$ & $\begin{array}{l}3.29^{* * *} \\
(7.49)\end{array}$ \\
\hline aanv & $\begin{array}{l}-0.5 \\
(-0.50)\end{array}$ & $\begin{array}{l}-0.48 \\
(-0.46)\end{array}$ & $\begin{array}{l}1.02 \\
(0.80)\end{array}$ & $\begin{array}{l}1.56 \\
(1.63)\end{array}$ & $\begin{array}{l}0.6 \\
(0.60)\end{array}$ & $\begin{array}{l}1.1^{*} \\
(1.68)\end{array}$ & $\begin{array}{l}1.01 \\
(1.54)\end{array}$ & aanv & $\begin{array}{l}1.1 \\
(1.14)\end{array}$ & $\begin{array}{l}0.14 \\
(0.14)\end{array}$ & $\begin{array}{l}0.82 \\
(0.72)\end{array}$ & $\begin{array}{l}1.24 \\
(1.15)\end{array}$ & $\begin{array}{l}2.36 \\
(2.18)\end{array}$ & $\begin{array}{l}1.25^{* * *} \\
(2.92)\end{array}$ & $\begin{array}{l}1.24^{* * *} \\
(2.85)\end{array}$ \\
\hline aanv30 & $\begin{array}{l}-0.48 \\
(-0.47)\end{array}$ & $\begin{array}{l}0.1 \\
(0.09)\end{array}$ & $\begin{array}{l}1.31 \\
(1.21)\end{array}$ & $\begin{array}{l}0.94 \\
(0.87)\end{array}$ & $\begin{array}{l}1.14 \\
(1.06)\end{array}$ & $\begin{array}{l}1.62^{* *} \\
(2.18)\end{array}$ & $\begin{array}{l}1.47^{* *} \\
(2.00)\end{array}$ & aanv30 & $\begin{array}{l}-0.42 \\
(-0.46)\end{array}$ & $\begin{array}{l}0.43 \\
(0.41)\end{array}$ & $\begin{array}{l}1 \\
(0.90)\end{array}$ & $\begin{array}{l}1.42 \\
(1.32)\end{array}$ & $\begin{array}{l}3.15 \\
(3.02)\end{array}$ & $\begin{array}{l}3.58^{* * *} \\
(7.72)\end{array}$ & $\begin{array}{l}3.53^{* * * *} \\
(7.60)\end{array}$ \\
\hline
\end{tabular}




\section{B. Bivariate Sorts}

Bivariate portfolio sorts are used to disentangle the interdependence between aanv30 and the remaining anomaly variables. At the end of each Tuesday, cryptoassets are unconditionally sort on two anomaly variables. Taking the size and aanv30 pair as an example, unconditional double sort are conducted as follows: Cryptoassets are allocated into three size groups and independently allocated into three aanv30 groups. The intersection of the independent $3 \times 3$ sorts on size and aanv30 produces nine portfolios. The portfolio return is calculated from Tuesday to Tuesday in the consecutive week.

Table III shows average value-weighted (Panel A) as well as equal-weighted (Panel B) weekly returns. The HML column (rows) report return differences between the third and the first column (row). Thus, the HML column in Panel A.1 equals the average returns of a portfolio that is long in big and short in small cryptoassets. Similarly, the HML row depicts the average returns of a portfolio that is long in value and short in growth cryptoassets. Panel A.1 in Table III shows that when size is held constant, average returns increase from growth cryptoassets to value cryptoassets. The value premium is highest within small cryptoassets, where the long-short strategy yields $3.05 \%$ per week for value-weighted portfolios and $3.63 \%$ for equal-weighted portfolios. Panel A.2 in Table III shows that the value premium is only significant within the first market $\beta$ tercile. Overall, the value premium is most profound within small, low market $\beta$, low momentum, and high idiosyncratic volatility portfolios. Looking at equal-weighted portfolios, the portfolio return differences between value and growth cryptoassets are large in economic magnitude and in most cases, statistically significant.

Looking at the rows of Panel A.1 in Table [II, I document the highest value-weighted size effect of $2.02 \%(t=2.13)$ is within value portfolios. The size effect is economically larger when portfolio returns are equal-weighted. In each row of Panel A.2, the relation between market $\beta$ and future cryptoasset returns is not clear for the beta-aanv30 portfolios. Panel B.3 reveals a reversal pattern in cryptoasset returns, that is, that past winners earn on average lower returns the past losers. This pattern increases from growth towards value cryptoassets.

Findings of Panel A.1 are visualized in the Appendix (cf. Figure A1). The online Appendix additionally provides results of bivariate portfolio sorts that include the aanv ratio. 


\section{Table III Two-dimensional weekly sorts}

Averages of weekly percent excess returns for value-weighted (Panel A) and equal-weighted (Panel B) portfolios formed on size and average active addresses over the past 30 days to network value (aanv30), market beta (beta) and aanv30, momentum and aanv30, and idiosyncratic volatility (ivol) and aanv30 ; 04-July-2017 to 06-October-2020, 170 weeks. At the end of each Tuesday $(=\mathrm{t})$, crypotassets are allocated into groups based on the first variable and independently allocated to three aanv30 groups. The intersections of the two sorts produce nine portfolios. In the sort time $t$, market beta is estimated from $t-28$ days until $t$, size is the market cap at time $t$, momentum is the cumulative return from t-90 days to $t$, idiosyncratic volatility is the standard deviation of the residuals after estimating the CAPM from t- 28 days until t. Then, value-weighted and equal-weighted portfolio returns are calculated from Tuesday $(\mathrm{t})$ to Tuesday in the consecutive week ( $\mathrm{t}+1)$. The HML column (row) is a long-short portfolio, which is long in the third column (row) and short in the first column (row). T-statistics are reported in parenthesis below the coefficients. $*, * *, * * *$ indicate statistical significance levels at the $10 \%, 5 \%, 1 \%$ levels, respectively.

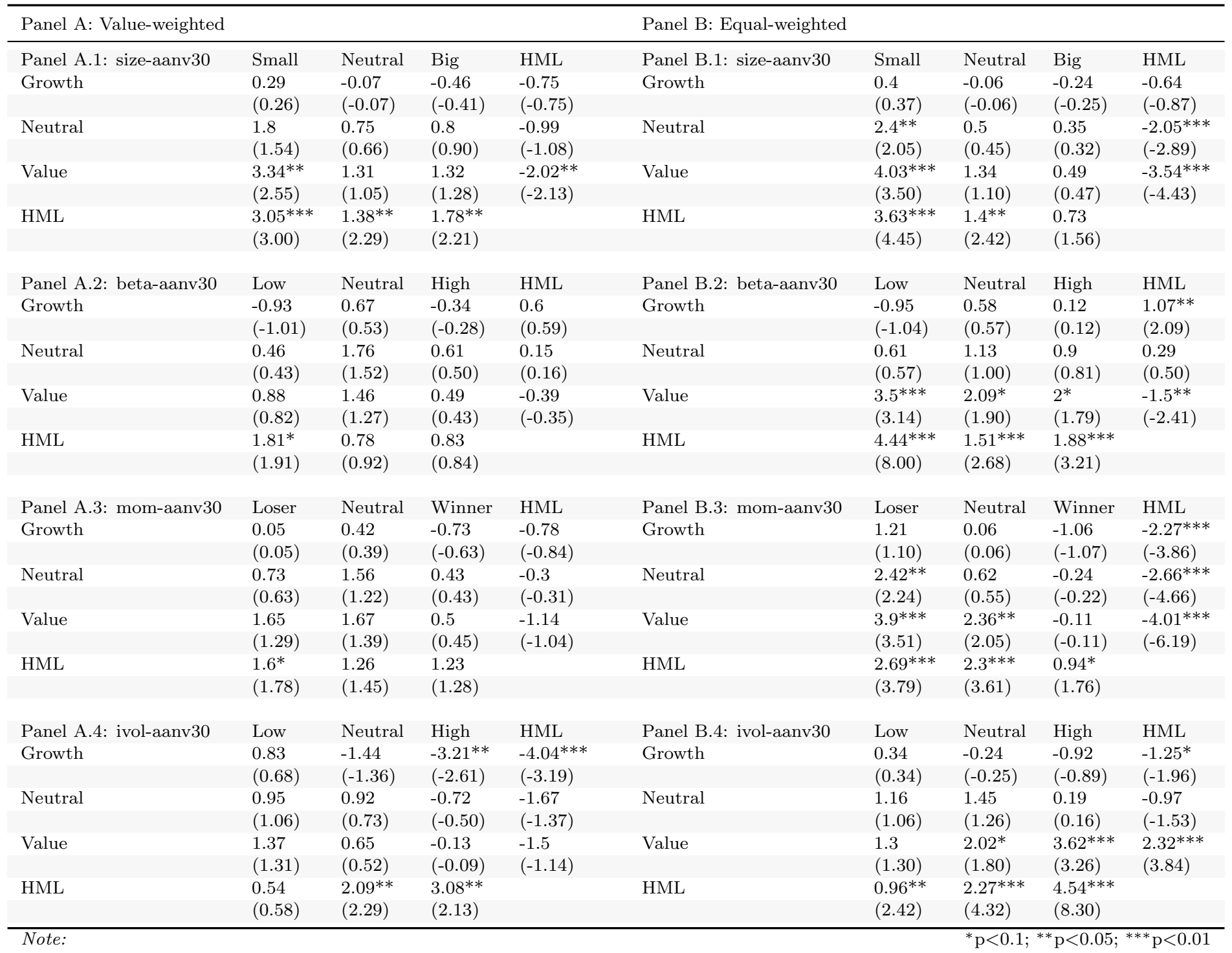




\section{Fama-MacBeth Regression}

Following the method proposed by Fama and MacBeth (1973), I carry out various crosssectional regressions to examine the relation between 1-week ahead returns and the value anomalies. Each Tuesday, I compute the anomaly variables for cryptoasset i at time t and estimate the cross-sectional regression. Eq. 2 represents the full model:

$r_{i, t+1}=\gamma_{0, t}+\gamma_{1, t} \beta_{i, t}+\gamma_{2, t} \log \left(\operatorname{size}_{i, t}\right)+\gamma_{3, t}$ momentum $_{i, t}+\gamma_{4, t} \log \left(\operatorname{aanv} 30_{i, t}\right)+\gamma_{5, t}$ ivol $_{i, t}+\epsilon_{i, t+1}$

where $r_{i, t+1}$ is the weekly return (in percent) of cryptoasset i from Tuesday (t) to Tuesday $(\mathrm{t}+1)$. The market $\beta$ of cryptoasset $\mathrm{i}$ at time $\mathrm{t}$ is estimated over a rolling 28 day window denoted by $\beta_{i, t} . \log \left(\operatorname{size}_{i, t}\right)$ is the natural logarithm of the market capitalization of asset $\mathrm{i}$ at time t, momentum is the cumulative return of cryptoasset $i$ over the past 90 days, and $\log \left(\operatorname{aanv}_{i, t}\right)$ is the natural logarithm of the mean number of active addresses over the past 30 days divided by network value of at time t. The time-series average of all weekly premiums results in the parameter estimates.

Table IV reports time-series averages of the coefficients for eleven cross-sectional regression models. The first model regresses cryptoasset returns on the market $\beta$. The estimated coefficient for market $\beta$ is 0.07 with a t-statistic of 0.25 . The second (third) model verifies the negative relationship between size (momentum) and future cryptoasset returns. The coefficient associated with aanv30 equals 0.77 and is more than 7 standard errors away from zero. Model five documents that with the exception for market $\beta$, all coefficients slightly decrease, but the statistical significance remains. Model six confirms that aanv30 carries a positive return premium even after controlling for size and market beta. In model 8-10, I replace annv30 with tvnv30, txnv30, aanv, respectively. For all value variables, the resulting coefficient is positive and highly significant. Model 11 represents the full model. Interestingly, market $\beta$ becomes significant after controlling for size, momentum, and aanv30. The aanv30 variable is statistically significant, with a coefficient of 0.5 and a t-statistic of 4.3. No significant relationship between idiosyncratic and expected returns of cryptoassets exists. The negative momentum coefficient confirms the reversal pattern in cryptoasset returns documented in the previous Sections. Overall, the results in Table IV are consistent with Table II and III.

Comparing my results to previous studies in this field, I confirm the size premium that has been documented by Liu et al. (2020) and Li et al. (2020). The observed reversal effect is consistent with Shen, Urquhart, and Wang (2020). 


\section{Table IV Fama-Macbeth 1-week ahead}

This table depicts average coefficients from week-by-week cross-sectional regressions of cryptoasset returns on market beta, size, momentum, idiosyncratic volatility, aanv, aanv30, tvnv30 and txnv30; 04-July-2017 to 06-October-2020, 170 weeks, 652 cryptoassets. Model 11 represents the full model:

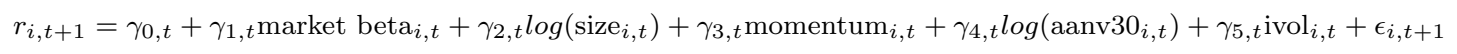

The average slope is the time-series average of the weekly regression slopes, and the t-statistic is the average slope divided by its time-series standard error. T-statistics are reported in parenthesis below the coefficient. T-statistics are reported in parenthesis below the coefficients. *, **, *** indicate statistical significance levels at the $10 \%$, $5 \%, 1 \%$ levels respectively.

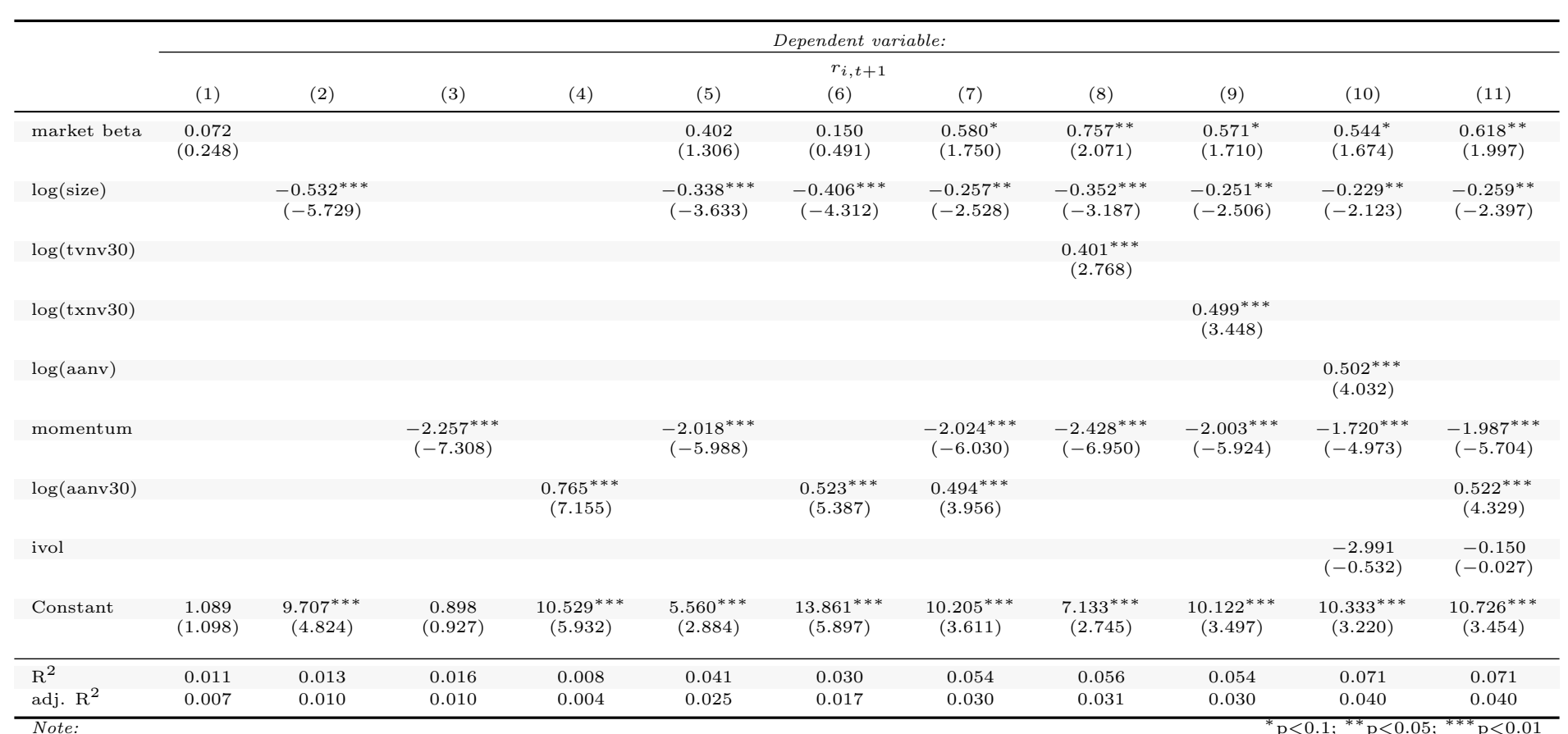




\section{A four-factor Model}

This Section defines the components and factors of the four-factor model. The performance of different factor models is tested in Section VI.B. Section VI.C investigates if any common risk factor is redundant.

\section{A. Factor Definition}

I focus on four factors that are specific to the cryptoasset market. The first three factors are based on previous research by Liu et al. (2020). I add the value factor as an additional common risk factor in the returns of cryptoassets. The first factor is the value-weighted excess market return (MKT). I use 3x3 portfolio sorts to construct the size, momentum, and value factor for the remaining factors. Following the methodology of Fama and French (2015), cryptoassets are unconditionally sorted and defined on the intersections of two variables. Hence, the size and value factors result from independent sorts of cryptoassets into three size groups and three value (aanv30) groups. For each portfolio, I calculate value-

weighted returns from each Tuesday to Tuesday in the following week. Equation 3, 4, and 5 define the components of the factors. I label the portfolios with two letters. The first letter describes the size group ( $\mathrm{S}=$ small, $\mathrm{N}=$ neutral, $\mathrm{B}=\mathrm{big}$ ). The second letter describes either the aanv30 group ( $\mathrm{V}=$ value, $\mathrm{N}=$ neutral, $\mathrm{G}=$ growth) or the momentum group ( $\mathrm{W}=$ winner, $\mathrm{N}=$ neutral, $\mathrm{L}=$ Loser $)$.

$$
\begin{gathered}
S M B_{\text {Value }}=S V-B V, \quad S M B_{\text {Neutral }}=S N-B N, \quad S M B_{\text {Growth }}=S G-B G \\
H M L_{\text {Small }}=S V-S G, \quad H M L_{\text {Neutral }}=N V-N G, \quad H M L_{\text {Big }}=B V-B G \\
W M L_{\text {Small }}=S W-S L, \quad W M L_{\text {Neutral }}=N W-N L, \quad W M L_{\text {Big }}=B W-B L
\end{gathered}
$$

The size factor (SMB) equals the average of the three small cryptoasset portfolio returns minus the three big cryptoasset portfolio returns. Analogously, the value factor (HML) is the average portfolio return of the three high aanv30 portfolio returns minus the average of the three low aanv30 portfolio returns. Notice that value (growth) cryptoassets are characterized by a high (low) aanv30 ratio. Thus, the SMB, HML, and WML factor are defined according to eq. 3, 4, and 5), respectively. 


$$
\begin{gathered}
S M B=\frac{S M B_{\text {Value }}+S M B_{\text {Neutral }}+S M B_{\text {Growth }}}{3} \\
H M L=\frac{H M L_{\text {Small }}+H M L_{\text {Neutral }}+H M L_{\text {Big }}}{3} \\
W M L=\frac{W M L_{\text {Small }}+W M L_{\text {Neutral }}+W M L_{\text {Big }}}{3}
\end{gathered}
$$

The four-factor asset pricing model is an extension of the three-factor model of Liu et al. (2020) and is defined as follows:

$$
R_{i, t}-R_{F, t}=\alpha_{i}+\beta_{i}\left[R_{M, t}-R_{F, t}\right]+s_{i} S M B_{t}+w_{i} W M L_{t}+v_{i} H M L_{t}+\epsilon_{i, t}
$$

Table V]reports summary statistics for weekly value-weighted factor returns. Panel A reports for each factor average excess returns (in percent), standard deviation, and t-statistics. The excess market return equals $0.98 \%$, and a t-statistic of 1.14 . The HML factor exhibits the highest return of $2.0 \%$ per week $(\mathrm{t}=4.3)$ and the SMB factor yields an average weekly return of $1.3 \%$. The WML factor displays a negative return of $-1.9 \%$, and a t-statistic of -3.28. Panel B reports the correlation matrix of the four factors. The SMB and WML factor are uncorrelated to the MKT factor. The HML factor exhibits the highest correlation to the SMB factor at 0.25 . Panel $\mathrm{C}$ reports summary statistics for returns on the portfolios used to construct the three factors (see equation 3, 4, and 5). I have previously presented the results for HML and SMB in Table III in Section V.B. Considering the WML factor, the reversal effect is most profound within small, and neutral size portfolios. 
Table V Summary statistic of weekly factor returns

Summary statistics for weekly factor percent returns; 04-July-2017 to 06-October-2020, 170 weeks. At the end of each Tuesday, cryptoassets are assigned to $3 \times 3$ groups through unconditional sorts. In each group, the portfolio return is valueweighted. Panel A reports weekly percent returns, standard deviation (Std. dev), and t-Statistic of the factor returns. Panel B shows the correlation for each set of factors. Panel C reports summary statistics of the components of the factors. $H M L_{s}$ is the average return on the portfolios of small value (high aanv30) cryptoassets minus the average return on the portfolios of small growth (low aanv30) cryptoassets. $H M L_{b}\left(H M L_{n}\right)$ is defined analogously for big (neutral) cryptoassets. $S M B_{g}, S M B_{n}, S M B_{v}, W M L_{s}, W M L_{n}$, and $W M L_{b}$ are defined in the same way. HML is the average of $H M L_{s}, H M L_{n}, H M L_{b}$.

\begin{tabular}{|c|c|c|c|c|c|c|c|c|c|c|}
\hline Panel A: & $\mathrm{MKT}$ & SMB & HML & WML & & Panel B: & $\mathrm{MKT}$ & SMB & HML & WML \\
\hline Mean & 0.976 & 1.255 & 2.068 & -1.923 & & MKT & 1 & -0.002 & 0.244 & 0.033 \\
\hline Std. dev & 0.112 & 0.089 & 0.063 & 0.076 & & SMB & -0.002 & 1 & 0.249 & -0.183 \\
\hline \multirow[t]{2}{*}{ t-Statistic } & 1.144 & 1.842 & 4.286 & -3.281 & & HML & 0.244 & 0.249 & 1 & 0.173 \\
\hline & & & & & & WML & 0.033 & -0.183 & 0.173 & 1 \\
\hline Panel C: & $H M L_{s}$ & $H M L_{n}$ & $H M L_{b}$ & $S M B_{g}$ & $S M B_{n}$ & $S M B_{v}$ & $W M L_{s}$ & $W M L_{n}$ & $W M L_{b}$ & \\
\hline Mean & 3 & 1.4 & 1.8 & 0.7 & 1 & 2 & -3.7 & -1.7 & -0.4 & \\
\hline Std. dev & 0.132 & 0.079 & 0.105 & 0.131 & 0.12 & 0.124 & 0.134 & 0.073 & 0.114 & \\
\hline t-Statistic & 2.999 & 2.294 & 2.214 & 0.747 & 1.08 & 2.133 & -3.597 & -3.052 & -0.401 & \\
\hline
\end{tabular}




\section{B. Explain Average Returns of Cryptoassets}

To test the explanatory ability of the four-factor model, I consider four different asset pricing models: (I) the one-factor model includes the excess market return (MKT); (II) twofactor models that combine MKT with SMB or HML; (III) three-factor models that combine MKT and SMB with WML or HML; (IV) the four-factor model that combines MKT, SMB, HML and WML. The asset pricing models are tested for 25 portfolios constructed from two-pass sorts. Cryptoassets are sorted on the first-mentioned variable and subsorted on the second variable. Conditional sorts are chosen due to the relatively small sample of 652 cryptoassets, which leads to a relatively even number of cryptoassets in each subgroup of the 25 portfolios. For each portfolio, equal-weighted returns are calculated. An asset pricing model that perfectly captures expected returns results in intercepts that are indistinguishable from zero, when regressing cryptoasset's excess returns on the factors. I test this conjecture using the GRS statistic of Gibbons, Ross, and Shanken (1989). The GRS statistic tests the null hypothesis that the intercepts equal zero for a combination of portfolios.

\section{Table VI Summary statistic of weekly factor tests}

Summary statistics for tests of one-, two-, three- and four-factor models; 04-July-2017 to 06-October-2020, 170 weeks. The table tests the ability of the factor models to explain weekly excess returns on 25 size-aanv30 portfolios (Panel A), size-Beta portfolios (Panel B), size-txnv30 portfolios (Panel C), and size-idiosyncratic volatility portfolios (Panel D). In each Panel, cryptoassets are conditionally sorted on the first variable and subsorted on the second variable. The portfolio returns of the 25 portfolios are equal-weighted. For each set of 25 regressions, this table depicts factors that augment the MKT factor in the regression model. The GRS statistic tests if the expected values of 25 portfolio intercepts are zero. The second column reports the average absolute intercepts and average adj. $R^{2}$ are reported in the third column.

\begin{tabular}{llllllll}
\hline & GRS & $\mathrm{A}\left(\left|\mathrm{a}_{i}\right|\right)$ & $\mathrm{A}\left(\mathrm{adj} . R^{2}\right)$ & & $\mathrm{GRS}$ & $\mathrm{A}\left(\left|\mathrm{a}_{i}\right|\right)$ & $\mathrm{A}\left(\operatorname{adj} . R^{2}\right)$ \\
\hline Panel A: 25 Size-aanv30 & & & & Panel C: 25 Size-txnv30 & & \\
MKT & 3.229 & 0.012 & 0.538 & MKT & 3.316 & 0.012 & 0.536 \\
MKT SMB & 3.136 & 0.014 & 0.65 & MKT SMB & 3.17 & 0.013 & 0.648 \\
MKT HML & 2.523 & 0.009 & 0.55 & MKT HML & 2.517 & 0.009 & 0.547 \\
MKT SMB WML & 4.516 & 0.018 & 0.677 & MKT SMB WML & 4.9 & 0.018 & 0.675 \\
MKT SMB HML & 2.559 & 0.011 & 0.662 & MKT SMB HML & 2.521 & 0.01 & 0.659 \\
MKT WML SMB HML & 3.51 & 0.017 & 0.686 & MKT WML SMB HML & 3.868 & 0.016 & 0.681 \\
& & & & & & & \\
Panel B: 25 Size-Beta & & & & Panel D: 25 Size-ivol & & \\
MKT & 4.384 & 0.011 & 0.549 & MKT & 4.639 & 0.012 & 0.551 \\
MKT SMB & 4.347 & 0.013 & 0.656 & MKT SMB & 4.433 & 0.013 & 0.661 \\
MKT HML & 3.578 & 0.01 & 0.555 & MKT HML & 0.012 & 0.558 \\
MKT SMB WML & 4.713 & 0.018 & 0.683 & MKT SMB WML & 4.66 & 0.018 & 0.692 \\
MKT SMB HML & 3.662 & 0.011 & 0.664 & MKT SMB HML & 4.262 & 0.012 & 0.668 \\
MKT WML SMB HML & 3.8 & 0.016 & 0.686 & MKT WML SMB HML & 4.265 & 0.016 & 0.695 \\
\hline
\end{tabular}

Table VI reports the performance evaluation of the factor models on 5x5 two-pass sorted equal-weighted portfolio returns. Note that conditional sorts are dependant on the sorting order. Cryptoassets are sorted on the first-mentioned variable and subsorted on the second variable for each pair. Thus, in Panel A of Table VI cryptoassets are first sorted on size and then sorted on aanv30. The first column in each panel reports the GRS statistic. Due 
to redundancy, the corresponding p-value of the GRS test is not reported. For all factor models, I reject the null hypothesis that the intercept is zero at the $1 \%$ level. This result indicates that all models are incomplete descriptions of expected cryptoasset returns. The factor models fare best (worst) on the size-aanv30 (size-ivol) portfolios judged from GRS tests. However, I am mostly interested in whether adding the HML factor improves the models' ability to describe average cryptoasset returns. Looking at Panel A, I find that the MKT-HML factor model provides the best description of expected returns on the size-aanv30 portfolios, with a GRS statistic of 2.5. In contrast, the four-factor model results in a GRS statistic of 3.51. The MKT-HML factor model also fares best in describing the size-txnv30 portfolio returns. Importantly, when comparing factor models that include the HML factor to models that exclude the HML factor, I find that the performance of the latter models is significantly worse in explaining average returns. In other words, adding the HML factor to existing factor-models always improves the model performance. In contrast, adding the WML factor to the two-factor model results in a higher GRS statistic.

In column two of Table VI, I report for each model the average absolute intercepts of all 25 portfolios. For all four sets of $5 \times 5$ portfolios, the average absolute intercepts are the lowest for the MKT-HML two-factor model. In the last column of Table VI, I report the average adj. $R^{2}$ for the 25 portfolios. On average, the four-factor model explains the largest fraction of the variation in cryptoasset returns. 


\section{HML: the only Factor?}

Adding the HML factor to any factor model improves the model's ability to describe average cryptoasset returns. Interestingly, the MKT-HML two-factor model fares relatively well compared to the four-factor model. Thus, the question arises if the HML factor might be the only relevant factor to describe expected returns. Potential redundancies of factors are evaluated by spanning regressions, which regress each of the four factors on the remaining three. The spanning regression is defined according to eq. 10. The redundancy of a factor is reflected in an insignificant intercept. Table VII depicts the results of four spanning regressions.

$$
M K T_{t}=\alpha_{0}+\beta_{1} S M B_{t}+\beta_{2} H M L_{t}+\beta_{3} W M L_{t}+\epsilon_{t}
$$

In the regression to explain the MKT factor, the intercepts is insignificant. The average MKT return is captured by the exposure of MKT to the HML factor. Similarly, model 2 shows that the SMB is explained by the HML and WML factor. Hence, in the four-factor model, MKT and SMB are redundant for describing average cryptoasset returns, at least in data for 2017-2020. In the HML regression, the intercept is $2 \%$ per week, with a t-statistic of 4.4. In the regression to explain WML, the intercept equals $-2.2 \%(\mathrm{t}=-3.8)$.

Table VII Spanning regression

Using three factors in regressions to explain average weekly returns of the fourth factor; 04-July-2017 to 06-October-2020, 170 weeks. Model 1:

$$
M K T_{t}=\alpha_{t}+\beta_{1, t} S M B+\beta_{i, t} H M L+\beta_{3, t} W M L+\epsilon_{t}
$$

MKT is the value-weighted market return minus the one-month Treasury bill rate; SMB (small minus big) is the size factor; HML (high minus low aanv30) is the value factor; WML is the momentum factor. T-statistics are reported in parenthesis below the coefficients. ${ }^{*},{ }^{* *},{ }^{* *}$ indicate statistical significance levels at the $10 \%, 5 \%, 1 \%$ levels, respectively.

\begin{tabular}{lcccc}
\hline & \multicolumn{4}{c}{ Dependent variable: } \\
\cline { 2 - 5 } & MKT & SMB & HML & WML \\
& $(1)$ & $(2)$ & $(3)$ & $(4)$ \\
\hline MKT & & -0.055 & $0.134^{* * *}$ & -0.017 \\
& & $(-0.917)$ & $(3.351)$ & $(-0.331)$ \\
HML & $0.474^{* * *}$ & $0.432^{* * *}$ & & $0.290^{* * *}$ \\
& $(3.351)$ & $(4.010)$ & & $(3.017)$ \\
SMB & -0.092 & & $0.205^{* * *}$ & $-0.208^{* * *}$ \\
& $(-0.917)$ & & $(4.010)$ & $(-3.152)$ \\
WML & & & \\
& -0.038 & $-0.271^{* * *}$ & $0.179^{* * *}$ & \\
Constant & $(-0.331)$ & $(-3.152)$ & $(3.017)$ & \\
& 0.0005 & -0.001 & $0.020^{* * *}$ & $-0.022^{* * *}$ \\
& $(0.053)$ & $(-0.148)$ & $(4.378)$ & $(-3.762)$ \\
\hline Observations & 170 & 170 & 170 & 170 \\
$\mathrm{R}^{2}$ & 0.064 & 0.119 & 0.167 & 0.085 \\
Adjusted $\mathrm{R}^{2}$ & 0.048 & 0.103 & 0.152 & 0.068 \\
Residual Std. Error (df $=166)$ & 0.109 & 0.084 & 0.058 & 0.074 \\
$\mathrm{~F} \mathrm{Statistic} \mathrm{(df} \mathrm{=} \mathrm{3;} \mathrm{166)}$ & $3.810^{* *}$ & $7.456^{* * *}$ & $11.119^{* * *}$ & $5.118^{* * *}$ \\
\hline Note: & \multicolumn{3}{c}{$\mathrm{p}<0.1 ;{ }^{* *} \mathrm{p}<0.05 ;{ }^{* * *} \mathrm{p}<0.01$} \\
& & \multicolumn{3}{c}{}
\end{tabular}




\section{Robustness}

As a robustness test, all results are examined using daily data, which enlarges the sample size from 170 weeks to 1190 days. Overall, the results remain unchanged but become statistically more significant and increase in economic magnitude.

Table VIII reports average daily excess returns (in percent) from univariate portfolio sorts, when daily rebalanced. For size, average daily returns decrease from $0.79 \%$ in the first quintile to $0.00 \%$ in the fourth quintile. In the fifth size quintile, value-weighted returns are slightly higher compared to quintile four. The HML portfolio that is long in small and short in big cryptoassets yields a daily return of $0.65 \%$. For equal-weighted portfolios, this size effect equals $1.2 \%(\mathrm{t}=14.92)$ per day. In the aanv30 row, I reports that value-weighted (equal-weighted) daily returns increase from $-0.12 \%(-0.14 \%)$ in the first quintile portfolio to $0.18 \%(0.93 \%)$ in the fifth quintile. The CAPM alpha of the aanv30 portfolio equals $0.29 \%$ and is more than 2.9 standard errors away from zero. In general, when the portfolios are daily rebalanced, the results remain consistent with Table II in Section V.A.

Average daily excess returns for 3x3 independent portfolio sorts are reported in Table IX. Within all subpanels in Table IX, portfolio returns increase from growth towards value cryptoassets. The HML portfolios that are long in value and short in growth cryptoassets yield a value-weighted return of $0.71 \%(0.27 \%)$ per day within the small (big) tercile portfolio. Figure A2 in the Appendix provides a visualization of daily portfolio returns, according Panel A.1 in Table IX. Consistent with Table III in Section V.B, the highest value premiums are found within small, low market $\beta$, low momentum, and high idiosyncratic volatility portfolios.

Table $\mathrm{X}$ presents time-series averages of the slopes from day-by-day Fama and MacBeth (1973) regressions of the cross-section of cryptoasset returns on market $\beta$, size, momentum, idiosyncratic volatility, and the value variables. In all model specifications, size (aanv30) carries a statistically negative (positive) return premium. Model 11 represents the full model. The explanatory variable aanv30 has an average slope of $0.15 \%$ per day, with a t-statistic of 9.26. The positive relation between aanv30 and one day ahead cryptoasset returns persists in all model specifications. Moreover, similar results are obtained when aanv30 is replaced with aanv, tvnv30 or txnv30, respectively.

Summary statistics of daily factor returns are provided in Table A4 in the Appendix. The MKT, SMB, HML, and WML factor have average daily returns of $0.13 \%, 0.34 \%, 0.43 \%$, 0.89 , respectively. Thus, the value factor is economically the largest and exhibits a t-statistic 
above five. I find the highest correlation between the HML and MKT factor of 0.12. Turning to the explanatory ability of different factor models, Table XI reports GRS statistics, average absolute intercepts, and average adj. $R^{2}$. Thus, I reject the null hypothesis that all intercepts are zero. In other words, GRS statistics indicate that all models are incomplete descriptions of expected returns. However, the GRS statistics are always lower when the HML factor is included in the factor models. Thus, I confirm the previous finding that the HML factor helps explain the expected returns of cryptoassets.

The regression results from spanning regressions are provided in Table A5 in the Appendix. In the regressions to explain SMB, HML, and WML, the intercepts (average returns unexplained by exposures to other factors) are in absolute terms more than three standard errors from zero. Thus, none of these factors exhibits characteristics of a redundant factor. Importantly, the intercept of the HML regression the intercept equals $0.4 \%$ with a t-statistic of 6.39. The MKT regression suggests that the MKT factor is the only redundant factor. 
Table VIII One-dimensional daily sorts

Averages of daily percent excess returns for value-weighted (Panel A: VW) and equal-weighted (Panel B: EW) portfolios formed on market beta, size, 90-day momentum (mom), idiosyncratic volatility (ivol), amihud illiquidity measure (amihud), transaction volume in USD to network value (tvnv), number of transactions to network value (txnv), and active adresses to network value (adnv). For the latter three anomaly variables, I provide the results using the moving average over the past 30 days (t-30 days) in the nominator (e.g. tvnv30 - is the average transaction volume over the past 30 days divided by the network value at time $\mathrm{t}$ ); 04-July-2017 to 06-October-2020, 1190 days. At the end of each day $(=\mathrm{t})$, cryptoassets are sorted into quintiles based on corresponding anomaly variable. In the sort time $\mathrm{t}$, market beta is estimated from $t-28$ days until $t$, size is the market cap at time $t$, momentum is the cumulative return from t-90 days to $t$, idiosyncratic volatility is the standard deviation of the residuals after estimating the CAPM from $t-28$ days until $t$. Then, value-weighted and equal-weighted portfolio returns are calculated from $t$ to $t+1$. The high-minus-low (HML) column reports the average weekly returns of the 5-1 portfolio. The alpha $(\alpha)$ is the intercept obtained from a regression of HML returns on the market return. T-statistics are reported in parenthesis below the coefficients. $*, * *, * * *$ indicate statistical significance levels at the $10 \%, 5 \%, 1 \%$ levels, respectively.

\begin{tabular}{|c|c|c|c|c|c|c|c|c|c|c|c|c|c|c|c|}
\hline A: VW & Low & 2 & 3 & 4 & High & HML & $\alpha$ & B: EW & Low & 2 & 3 & 4 & High & HML & $\alpha$ \\
\hline market & $\begin{array}{l}-0.06 \\
(-0.53)\end{array}$ & $\begin{array}{l}0.13 \\
(1.03)\end{array}$ & $\begin{array}{l}0.2 \\
(1.42)\end{array}$ & $\begin{array}{l}0.11 \\
(0.75)\end{array}$ & $\begin{array}{l}-0.06 \\
(-0.36)\end{array}$ & $\begin{array}{l}0 \\
(0.01)\end{array}$ & $\begin{array}{l}-0.06 \\
(-0.50)\end{array}$ & market & $\begin{array}{l}0.38 \\
(3.32)\end{array}$ & $\begin{array}{l}0.23 \\
(1.75)\end{array}$ & $\begin{array}{l}0.23 \\
(1.67)\end{array}$ & $\begin{array}{l}0.22 \\
(1.56)\end{array}$ & $\begin{array}{l}0.41 \\
(2.74)\end{array}$ & $\begin{array}{l}0.04 \\
(0.39)\end{array}$ & $\begin{array}{l}-0.01 \\
(-0.12)\end{array}$ \\
\hline size & $\begin{array}{l}0.79 \\
(5.96)\end{array}$ & $\begin{array}{l}0.24 \\
(1.84)\end{array}$ & $\begin{array}{l}0.07 \\
(0.50)\end{array}$ & $\begin{array}{l}0 \\
(0.01)\end{array}$ & $\begin{array}{l}0.15 \\
(1.29)\end{array}$ & $\begin{array}{l}-0.65^{* * *} \\
(-7.95)\end{array}$ & $\begin{array}{l}-0.65 * * * \\
(-8.04)\end{array}$ & size & $\begin{array}{l}1.16 \\
(8.89)\end{array}$ & $\begin{array}{l}0.28 \\
(2.11)\end{array}$ & $\begin{array}{l}0.05 \\
(0.37)\end{array}$ & $\begin{array}{l}0.01 \\
(0.09)\end{array}$ & $\begin{array}{l}-0.02 \\
(-0.17)\end{array}$ & $\begin{array}{c}-1.18^{* * *} \\
(-14.92)\end{array}$ & $\begin{array}{c}-1.19 * * * \\
(-15.37)\end{array}$ \\
\hline mom & $\begin{array}{l}0.42 \\
(2.69)\end{array}$ & $\begin{array}{l}0.23 \\
(1.53)\end{array}$ & $\begin{array}{l}0.16 \\
(1.12)\end{array}$ & $\begin{array}{l}0.12 \\
(0.94)\end{array}$ & $\begin{array}{l}0.1 \\
(0.74)\end{array}$ & $\begin{array}{l}-0.35^{* * *} \\
(-3.11)\end{array}$ & $\begin{array}{l}-0.36^{* * *} \\
(-3.16)\end{array}$ & mom & $\begin{array}{l}1.29 \\
(9.40)\end{array}$ & $\begin{array}{l}0.41 \\
(3.09)\end{array}$ & $\begin{array}{l}0.18 \\
(1.36)\end{array}$ & $\begin{array}{l}-0.04 \\
(-0.29)\end{array}$ & $\begin{array}{l}-0.37 \\
(-2.83)\end{array}$ & $\begin{array}{l}-1.7^{* * *} \\
(-22.54)\end{array}$ & $\begin{array}{l}-1.7^{* * *} \\
(-22.59)\end{array}$ \\
\hline ivol & $\begin{array}{l}0.16 \\
(1.43)\end{array}$ & $\begin{array}{l}0.02 \\
(0.15)\end{array}$ & $\begin{array}{l}0.05 \\
(0.33)\end{array}$ & $\begin{array}{l}-0.31 \\
(-1.96)\end{array}$ & $\begin{array}{l}-0.52 \\
(-2.44)\end{array}$ & $\begin{array}{l}-0.68^{* * *} \\
(-3.73)\end{array}$ & $\begin{array}{l}-0.69^{* * *} \\
(-3.74)\end{array}$ & ivol & $\begin{array}{l}0.16 \\
(1.22)\end{array}$ & $\begin{array}{l}0.16 \\
(1.19)\end{array}$ & $\begin{array}{l}0.17 \\
(1.24)\end{array}$ & $\begin{array}{l}0.28 \\
(2.04)\end{array}$ & $\begin{array}{l}0.7 \\
(5.22)\end{array}$ & $\begin{array}{l}0.55^{* * *} \\
(7.01)\end{array}$ & $\begin{array}{l}0.56^{* * *} \\
(7.18)\end{array}$ \\
\hline amihud & $\begin{array}{l}0.15 \\
(1.31)\end{array}$ & $\begin{array}{l}0.06 \\
(0.42)\end{array}$ & $\begin{array}{l}-0.02 \\
(-0.15)\end{array}$ & $\begin{array}{l}0.01 \\
(0.04)\end{array}$ & $\begin{array}{l}-0.13 \\
(-0.76)\end{array}$ & $\begin{array}{l}-0.28^{* *} \\
(-2.02)\end{array}$ & $\begin{array}{l}-0.28^{*} \\
(-1.98)\end{array}$ & amihud & $\begin{array}{l}0.02 \\
(0.16)\end{array}$ & $\begin{array}{l}0.03 \\
(0.19)\end{array}$ & $\begin{array}{l}0.1 \\
(0.70)\end{array}$ & $\begin{array}{l}0.34 \\
(2.51)\end{array}$ & $\begin{array}{l}0.99 \\
(7.38)\end{array}$ & $\begin{array}{l}0.97^{* * *} \\
(11.50)\end{array}$ & $\begin{array}{l}0.98^{* * *} \\
(11.68)\end{array}$ \\
\hline tvnv & $\begin{array}{l}-0.06 \\
(-0.41)\end{array}$ & $\begin{array}{l}-0.09 \\
(-0.64)\end{array}$ & $\begin{array}{l}0.07 \\
(0.51)\end{array}$ & $\begin{array}{l}0.07 \\
(0.51)\end{array}$ & $\begin{array}{l}0.15 \\
(1.33)\end{array}$ & $\begin{array}{l}0.21^{* *} \\
(2.27)\end{array}$ & $\begin{array}{l}0.22^{* *} \\
(2.35)\end{array}$ & tvnv & $\begin{array}{l}0.46 \\
(3.66)\end{array}$ & $\begin{array}{l}0.24 \\
(1.83)\end{array}$ & $\begin{array}{l}0.25 \\
(1.86)\end{array}$ & $\begin{array}{l}0.26 \\
(1.87)\end{array}$ & $\begin{array}{l}0.18 \\
(1.33)\end{array}$ & $\begin{array}{l}-0.28^{* * *} \\
(-4.15)\end{array}$ & $\begin{array}{l}-0.29^{* * *} \\
(-4.36)\end{array}$ \\
\hline tvnv30 & $\begin{array}{l}-0.09 \\
(-0.60)\end{array}$ & $\begin{array}{l}-0.14 \\
(-1.04)\end{array}$ & $\begin{array}{l}0 \\
(0.00)\end{array}$ & $\begin{array}{l}0.1 \\
(0.72)\end{array}$ & $\begin{array}{l}0.16 \\
(1.41)\end{array}$ & $\begin{array}{l}0.25^{* * *} \\
(2.72)\end{array}$ & $\begin{array}{l}0.25^{* * *} \\
(2.74)\end{array}$ & tvnv30 & $\begin{array}{l}0.14 \\
(1.11)\end{array}$ & $\begin{array}{l}0.23 \\
(1.70)\end{array}$ & $\begin{array}{l}0.4 \\
(2.85)\end{array}$ & $\begin{array}{l}0.28 \\
(1.98)\end{array}$ & $\begin{array}{l}0.4 \\
(2.99)\end{array}$ & $\begin{array}{l}0.26^{* * *} \\
(3.71)\end{array}$ & $\begin{array}{l}0.25^{* * *} \\
(3.59)\end{array}$ \\
\hline txnv & $\begin{array}{l}-0.18 \\
(-1.31)\end{array}$ & $\begin{array}{l}0.24 \\
(1.88)\end{array}$ & $\begin{array}{l}0.07 \\
(0.48)\end{array}$ & $\begin{array}{l}0.12 \\
(0.80)\end{array}$ & $\begin{array}{l}0.15 \\
(1.02)\end{array}$ & $\begin{array}{l}0.33^{* * *} \\
(3.39)\end{array}$ & $\begin{array}{l}0.31^{* * *} \\
(3.25)\end{array}$ & txnv & $\begin{array}{l}0.25 \\
(2.04)\end{array}$ & $\begin{array}{l}0.01 \\
(0.09)\end{array}$ & $\begin{array}{l}0.18 \\
(1.33)\end{array}$ & $\begin{array}{l}0.32 \\
(2.28)\end{array}$ & $\begin{array}{l}0.63 \\
(4.62)\end{array}$ & $\begin{array}{l}0.38^{* * *} \\
(5.91)\end{array}$ & $\begin{array}{l}0.38^{* * *} \\
(5.82)\end{array}$ \\
\hline txnv30 & $\begin{array}{l}-0.06 \\
(-0.50)\end{array}$ & $\begin{array}{l}0.16 \\
(1.22)\end{array}$ & $\begin{array}{l}0.15 \\
(0.98)\end{array}$ & $\begin{array}{l}0.12 \\
(0.83)\end{array}$ & $\begin{array}{l}0.17 \\
(1.15)\end{array}$ & $\begin{array}{l}0.23^{* *} \\
(2.49)\end{array}$ & $\begin{array}{l}0.21^{* *} \\
(2.30)\end{array}$ & txnv30 & $\begin{array}{l}-0.15 \\
(-1.18)\end{array}$ & $\begin{array}{l}0.15 \\
(1.11)\end{array}$ & $\begin{array}{l}0.15 \\
(1.13)\end{array}$ & $\begin{array}{l}0.42 \\
(3.10)\end{array}$ & $\begin{array}{l}0.87 \\
(6.46)\end{array}$ & $\begin{array}{l}1.01 * * * \\
(15.74)\end{array}$ & $\begin{array}{l}1.01^{* * *} \\
(15.69)\end{array}$ \\
\hline aanv & $\begin{array}{l}-0.09 \\
(-0.64)\end{array}$ & $\begin{array}{l}-0.15 \\
(-1.05)\end{array}$ & $\begin{array}{l}0.08 \\
(0.54)\end{array}$ & $\begin{array}{l}0.24 \\
(1.89)\end{array}$ & $\begin{array}{l}0.1 \\
(0.70)\end{array}$ & $\begin{array}{l}0.19^{* *} \\
(2.00)\end{array}$ & $\begin{array}{l}0.18^{*} \\
(1.92)\end{array}$ & aanv & $\begin{array}{l}0.21 \\
(1.74)\end{array}$ & $\begin{array}{l}0 \\
(-0.01)\end{array}$ & $\begin{array}{l}0.15 \\
(1.10)\end{array}$ & $\begin{array}{l}0.3 \\
(2.22)\end{array}$ & $\begin{array}{l}0.71 \\
(5.31)\end{array}$ & $\begin{array}{l}0.5^{* * *} \\
(7.65)\end{array}$ & $\begin{array}{l}0.49 * * * \\
(7.58)\end{array}$ \\
\hline aanv30 & $\begin{array}{l}-0.12 \\
(-0.84)\end{array}$ & $\begin{array}{l}0.03 \\
(0.19)\end{array}$ & $\begin{array}{l}0.17 \\
(1.26)\end{array}$ & $\begin{array}{l}0.13 \\
(0.90)\end{array}$ & $\begin{array}{l}0.18 \\
(1.27)\end{array}$ & $\begin{array}{l}0.3^{* * *} \\
(3.07)\end{array}$ & $\begin{array}{l}0.29^{* * *} \\
(2.96)\end{array}$ & aanv30 & $\begin{array}{l}-0.14 \\
(-1.09)\end{array}$ & $\begin{array}{l}0.04 \\
(0.31)\end{array}$ & $\begin{array}{l}0.21 \\
(1.50)\end{array}$ & $\begin{array}{l}0.4 \\
(2.96)\end{array}$ & $\begin{array}{l}0.93 \\
(7.17)\end{array}$ & $\begin{array}{l}1.07 * * * \\
(16.49)\end{array}$ & $\begin{array}{l}1.08^{* * *} \\
(16.52)\end{array}$ \\
\hline
\end{tabular}




\section{Table IX Two-dimensional daily sorts}

Averages of daily percent excess returns for value-weighted (Panel A) and equal-weighted (Panel B) portfolios formed on size and average active addresses over the past 30 days to network value (aanv30), market beta (beta) and aanv30, momentum and aanv30, and idiosyncratic volatility (ivol) and aanv30 ; 04-July-2017 to 06-October-2020, 1190 days. At the end of each day $(=\mathrm{t})$, crypotassets are allocated into groups based on the first variable and independently allocated to three aanv30 groups. The intersections of the two sorts produce nine portfolios. In the sort time $t$, market beta is estimated from $t$ - 28 days until $t$, size is the market cap at time $t$, momentum is the cumulative return from t-90 days to $t$, idiosyncratic volatility is the standard deviation of the residuals after estimating the CAPM from t-28 days until t. Then, value-weighted and equal-weighted portfolio returns are calculated from day $(\mathrm{t})$ to the next day $(\mathrm{t}+1)$. The HML column (row) is a long-short portfolio, which is long in the third column (row) and short in the first column (row). T-statistics are reported in parenthesis below the coefficients. $*, * *, * * *$ indicate statistical significance levels at the $10 \%, 5 \%, 1 \%$ levels, respectively.

\begin{tabular}{|c|c|c|c|c|c|c|c|c|c|}
\hline \multicolumn{5}{|l|}{ Panel A: Value-weighted } & \multicolumn{5}{|l|}{ Panel B: Equal-weighted } \\
\hline Panel A.1: size-aanv30 & Small & Neutral & Big & HML & Panel B.1: size-aanv30 & Small & Neutral & Big & HML \\
\hline \multirow[t]{2}{*}{ Growth } & 0.04 & -0.07 & -0.09 & -0.14 & Growth & 0.16 & -0.07 & -0.11 & $-0.27 * *$ \\
\hline & $(0.29)$ & $(-0.48)$ & $(-0.62)$ & $(-0.99)$ & & $(1.08)$ & $(-0.49)$ & $(-0.80)$ & $(-2.32)$ \\
\hline \multirow[t]{2}{*}{ Neutral } & $0.44^{* * *}$ & 0.12 & 0.12 & $-0.33^{* * *}$ & Neutral & $0.51 * * *$ & 0.08 & 0 & $-0.51^{* * *}$ \\
\hline & $(3.08)$ & $(0.84)$ & $(0.93)$ & $(-3.26)$ & & $(3.57)$ & $(0.54)$ & $(-0.00)$ & $(-5.21)$ \\
\hline \multirow[t]{2}{*}{ Value } & $0.75^{* * *}$ & 0.23 & 0.18 & $-0.57 * * *$ & Value & $1.15^{* * *}$ & $0.27^{*}$ & 0.13 & $-1.02 * * *$ \\
\hline & $(4.95)$ & $(1.48)$ & $(1.37)$ & $(-5.15)$ & & $(8.15)$ & $(1.76)$ & $(0.95)$ & $(-9.54)$ \\
\hline \multirow[t]{2}{*}{ HML } & $0.71 * * *$ & $0.3^{* * *}$ & $0.27 * * *$ & & HML & $0.99 * * *$ & $0.34 * * *$ & $0.24 * * *$ & \\
\hline & $(5.00)$ & $(3.59)$ & $(2.71)$ & & & $(7.56)$ & $(4.19)$ & $(3.85)$ & \\
\hline Panel A.2: beta-aanv30 & Low & Neutral & High & HML & Panel B.2: beta-aanv30 & Low & Neutral & High & HML \\
\hline \multirow[t]{2}{*}{ Growth } & -0.14 & 0.05 & -0.11 & 0.03 & Growth & $-0.2^{*}$ & 0.1 & -0.05 & $0.16^{*}$ \\
\hline & $(-1.02)$ & $(0.35)$ & $(-0.66)$ & $(0.24)$ & & $(-1.74)$ & $(0.68)$ & $(-0.31)$ & $(1.70)$ \\
\hline \multirow[t]{2}{*}{ Neutral } & 0.02 & $0.26^{*}$ & 0.01 & -0.01 & Neutral & 0.13 & 0.22 & 0.13 & 0 \\
\hline & $(0.12)$ & $(1.77)$ & $(0.07)$ & $(-0.05)$ & & $(0.96)$ & $(1.49)$ & $(0.84)$ & $(0.01)$ \\
\hline \multirow[t]{2}{*}{ Value } & $0.35^{* *}$ & 0.06 & 0.13 & -0.23 & Value & $0.92^{* * *}$ & $0.46^{* * *}$ & $0.78^{* * *}$ & -0.14 \\
\hline & $(2.40)$ & $(0.41)$ & $(0.74)$ & $(-1.54)$ & & $(7.24)$ & $(3.36)$ & $(4.92)$ & $(-1.27)$ \\
\hline \multirow[t]{2}{*}{ HML } & $0.49^{* * *}$ & 0 & $0.24^{* *}$ & & HML & $1.13^{* * *}$ & $0.37^{* * *}$ & $0.83^{* * *}$ & \\
\hline & $(3.66)$ & $(0.04)$ & $(2.04)$ & & & $(13.32)$ & $(4.56)$ & $(9.20)$ & \\
\hline Panel A.3: mom-aanv30 & Loser & Neutral & Winner & HML & Panel B.3: mom-aanv30 & Loser & Neutral & Winner & HML \\
\hline \multirow[t]{2}{*}{ Growth } & 0.14 & 0.02 & -0.17 & $-0.31^{* *}$ & Growth & $0.5^{* * *}$ & -0.11 & $-0.38^{* * *}$ & $-0.87^{* * *}$ \\
\hline & $(0.92)$ & $(0.15)$ & $(-1.08)$ & $(-2.49)$ & & $(3.47)$ & $(-0.74)$ & $(-2.71)$ & $(-10.34)$ \\
\hline \multirow[t]{2}{*}{ Neutral } & $0.26^{*}$ & 0.12 & 0.09 & -0.17 & Neutral & $0.77^{* * *}$ & 0.17 & $-0.36^{* *}$ & $-1.13^{* * *}$ \\
\hline & $(1.65)$ & $(0.77)$ & $(0.64)$ & $(-1.39)$ & & $(5.26)$ & $(1.13)$ & $(-2.42)$ & $(-11.54)$ \\
\hline \multirow[t]{2}{*}{ Value } & $0.49^{* * *}$ & $0.26^{*}$ & 0.12 & $-0.37 * * *$ & Value & $1.44^{* * *}$ & $0.53^{* * *}$ & -0.09 & $-1.53^{* * *}$ \\
\hline & $(3.10)$ & $(1.74)$ & $(0.78)$ & $(-3.02)$ & & $(10.02)$ & $(3.73)$ & $(-0.65)$ & $(-13.38)$ \\
\hline \multirow[t]{2}{*}{ HML } & $0.34 * * *$ & $0.24^{* *}$ & $0.29^{* *}$ & & HML & $0.94^{* * *}$ & $0.64^{* * *}$ & $0.28 * * *$ & \\
\hline & $(2.92)$ & $(2.29)$ & $(2.27)$ & & & $(8.69)$ & $(6.75)$ & $(3.16)$ & \\
\hline Panel A.4: ivol-aanv30 & Low & Neutral & High & HML & Panel B.4: ivol-aanv30 & Low & Neutral & High & HML \\
\hline \multirow[t]{2}{*}{ Growth } & 0.06 & -0.17 & $-0.68 * * *$ & $-0.74^{* * *}$ & Growth & 0.08 & -0.07 & $-0.29 *$ & $-0.36^{* * *}$ \\
\hline & $(0.44)$ & $(-1.11)$ & $(-3.46)$ & $(-4.39)$ & & $(0.57)$ & $(-0.50)$ & $(-1.94)$ & $(-3.72)$ \\
\hline \multirow[t]{2}{*}{ Neutral } & 0.17 & -0.01 & -0.14 & $-0.31^{* *}$ & Neutral & 0.21 & 0.14 & 0.16 & -0.05 \\
\hline & $(1.34)$ & $(-0.04)$ & $(-0.76)$ & $(-2.05)$ & & $(1.49)$ & $(0.97)$ & $(1.07)$ & $(-0.58)$ \\
\hline \multirow[t]{2}{*}{ Value } & 0.18 & 0.25 & 0.18 & 0 & Value & $0.23^{*}$ & $0.44^{* * *}$ & $1.26^{* * *}$ & $1.03^{* * *}$ \\
\hline & $(1.38)$ & $(1.41)$ & $(0.88)$ & $(-0.03)$ & & $(1.77)$ & $(3.05)$ & (9.04) & (11.74) \\
\hline \multirow[t]{2}{*}{ HML } & 0.12 & $0.42 * * *$ & $0.86^{* * *}$ & & HML & $0.15^{* * *}$ & $0.51^{* * *}$ & $1.55^{* * *}$ & \\
\hline & $(1.28)$ & $(3.07)$ & $(4.05)$ & & & $(2.73)$ & $(6.17)$ & $(13.82)$ & \\
\hline
\end{tabular}




\section{Table X Fama-Macbeth 1-day ahead}

This table depicts average coefficients from day-by-day cross-sectional regressions of cryptoasset returns on market beta, size, momentum, idiosyncratic volatility, aanv, aanv30, tvnv30 and txnv30; 04-July-2017 to 06-October-2020, 1190 days, 652 cryptoassets. Model 11 represents the full model:

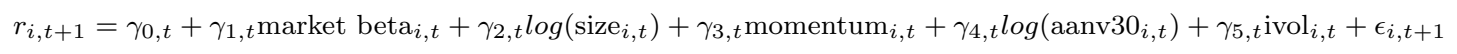

The average slope is the time-series average of the weekly regression slopes, and the t-statistic is the average slope divided by its time-series standard error. T-statistics are reported in parenthesis below the coefficient. T-statistics are reported in parenthesis below the coefficients. *, **, *** indicate statistical significance levels at the $10 \%$, $5 \%, 1 \%$ levels respectively.

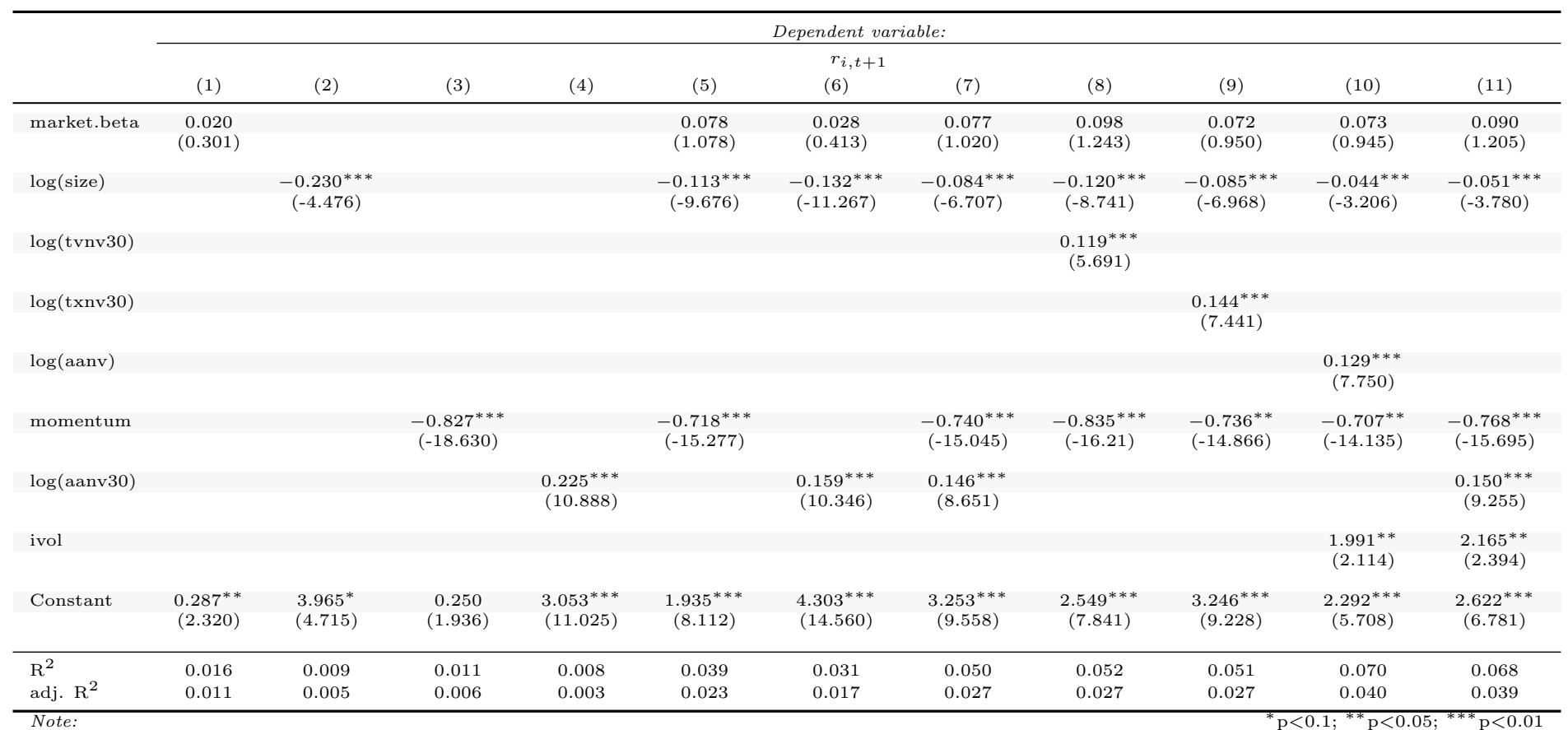




\section{Table XI Summary statistic of daily factor tests}

Summary statistics for tests of one-, two-, three- and four-factor models; 04-July-2017 to 06-October-2020, 1190 days The table tests the ability of the factor models to explain daily excess returns on 25 Size-aanv30 portfolios (Panel A), Size-Beta portfolios (Panel B), Size-Momentum portfolios (Panel C), and Size-Idiosyncratic volatility portfolios (Panel D). Cryptoassets are conditionally sorted on the first variable and subsorted on the second variable. The returns of the portfolios are equal-weighted. For each set of 25 regressions, this table depicts factors that augment the $R_{M}-r_{f}$ in the regression model. The GRS statistic tests if the expected values of of 25 portfolio intercepts are zero. The corresponding p-value is reported in the second column in each panel. The third column reports average absolute intercepts, and average adj. $R^{2}$ are reported in the fourth column.

\begin{tabular}{|c|c|c|c|c|c|c|c|}
\hline & GRS & $\mathrm{A}\left(\left|\mathrm{a}_{i}\right|\right)$ & $\mathrm{A}\left(\operatorname{adj} . R^{2}\right)$ & & GRS & $\mathrm{A}\left(\left|\mathrm{a}_{i}\right|\right)$ & $\mathrm{A}\left(\operatorname{adj} \cdot R^{2}\right)$ \\
\hline Panel A: 25 Size-aanv30 & & & & Panel C: 25 Size-txnv30 & & & \\
\hline MKT & 12.296 & 0.003 & 0.541 & MKT & 11.708 & 0.003 & 0.543 \\
\hline MKT SMB & 11.182 & 0.003 & 0.575 & MKT SMB & 10.611 & 0.003 & 0.578 \\
\hline MKT HML & 10.129 & 0.003 & 0.548 & MKT HML & 9.575 & 0.003 & 0.549 \\
\hline MKT SMB WML & 10.826 & 0.004 & 0.579 & MKT SMB WML & 10.589 & 0.004 & 0.582 \\
\hline MKT SMB HML & 9.038 & 0.003 & 0.582 & MKT SMB HML & 8.486 & 0.003 & 0.584 \\
\hline MKT WML SMB HML & 8.945 & 0.004 & 0.586 & MKT WML SMB HML & 8.681 & 0.004 & 0.588 \\
\hline Panel B: 25 Size-Beta & & & & Panel D: 25 Size-ivol & & & \\
\hline MKT & 11.643 & 0.003 & 0.566 & $\mathrm{MKT}$ & 12.749 & 0.003 & 0.579 \\
\hline MKT SMB & 10.627 & 0.003 & 0.6 & MKT SMB & 11.533 & 0.003 & 0.612 \\
\hline MKT HML & 10.261 & 0.003 & 0.567 & MKT HML & 11.459 & 0.003 & 0.58 \\
\hline MKT SMB WML & 10.584 & 0.004 & 0.604 & MKT SMB WML & 10.594 & 0.004 & 0.618 \\
\hline MKT SMB HML & 9.149 & 0.003 & 0.601 & MKT SMB HML & 10.187 & 0.003 & 0.613 \\
\hline MKT WML SMB HML & 9.304 & 0.004 & 0.605 & MKT WML SMB HML & 9.389 & 0.004 & 0.619 \\
\hline
\end{tabular}




\section{Conclusion}

There is a pattern in average cryptoasset returns related to average active addresses over the past 30 days to the network value ratio (aanv30). Active addresses refer to the number of unique wallet addresses that conduct an on-chain transaction, whereas the network value of a cryptoasset corresponds to its market capitalization. Value cryptoassets, that is, cryptoassets with high ratios of active addresses to network value, exhibit higher average returns than growth cryptoassets, which have low ratios of active addresses to network value. This pattern in average returns is referred to as value premium in the cryptoasset market and holds for different weighting schemes, and holding periods. Besides, cross-sectional regressions confirm that aanv30 carries a positive return premium even after controlling for market $\beta$, size, momentum, and idiosyncratic volatility. The value premium for cryptoassets is most profound within small, low market $\beta$, low momentum, and high idiosyncratic volatility portfolios.

In a next step, four cryptoasset specific common risk factors are constructed. I obtain excess market return (MKT), small-minus-big (SMB), momentum (WML), and high-minus-low (HML). The first three factors have previously been introduced by Liu et al. (2020). I propose the value factor as an additional common risk factor in the returns on cryptoassets and test the four-factor factor model's performance to explain the common variation in cryptoasset returns. The GRS test easily rejects all factor models directed at capturing the value pattern in average returns. However, adding the value factor to the three-factor model of Liu et al. (2020) significantly improves the model's ability to describe average cryptoasset returns. Moreover, spanning regressions suggest that the HML factor is not explained by the exposures to other risk factors. The value factor yields an average return of $2.1 \%$ per week and exhibits a Sharpe ratio of 0.33 .

These findings have significant implications for the understanding of cryptoassets. First, the documented value premium shows that cryptoasset return patterns go beyond those from stock markets. Second, the results suggest that cryptoasset prices are related to their blockchain fundamentals, which challenges the view of long-run speculations in cryptoasset markets. Third, as the four-factor model still provides an incomplete description of expected cryptoasset returns, more research is required in this field. Importantly, my findings offer

new research opportunities that go beyond the interpretation of cryptoassets as a speculative bubble. In the future, many new patterns that are specific to the cryptoasset market may be discovered. 


\section{Appendix A. Appendix}

\section{Table A1 Summary statistics}

Summary statistics (number of observations (N), Mean, standard deviation (Sd), minimum (min), 25\% quantile (Q1), median, 75\% quantile (Q3), and maximum (max)) of weekly observations; 04-July-2017 to 06-October-2020, 170 weeks, 652 cryptoassets. Summary statistics contain weekly excess returns over the one-month Treasury bill rate (ex.ret), excess market return (ex.mkt.ret), size (natural logarithm of market cap), market beta, idiosyncratic volatility (ivol), momentum (mom), amihud liquidity measure (amihud), number of active addresses (aa), total number of addresses (n.address), the total number of addresses with zero balance (0-balance address), number of transactions (tx), transaction volume in thousand USD (tv), number of transactions to network value (txnv), transaction volume to network value (tvnv), and active addresses to network value (aanv). For the last three multiples, I report smoothed multiples (txnv30, tvnv30, and aanv30), which contain the moving average of the corresponding variable over the past 30 days in the numerator and market capitalization at time $\mathrm{t}$ in the denominator. All variables of interest are winsorized at the 1\% and $99 \%$ level.

\begin{tabular}{lrrrrrrrr}
\hline & $\mathrm{N}$ & Mean & Sd & Min & Q1 & Median & Q3 & Max \\
\hline ex.ret & 77653 & 0.01 & 0.25 & -0.51 & -0.12 & -0.01 & 0.09 & 1.09 \\
ex.mkt.ret & 171 & 0.01 & 0.11 & -0.27 & -0.05 & 0.01 & 0.07 & 0.35 \\
market beta & 75823 & 0.91 & 0.80 & -1.89 & 0.52 & 0.97 & 1.33 & 3.42 \\
size & 77653 & 15.26 & 2.47 & 5.41 & 13.62 & 15.27 & 16.79 & 26.42 \\
ivol & 75823 & 0.09 & 0.08 & 0.01 & 0.04 & 0.07 & 0.11 & 0.47 \\
mom & 70519 & 0.03 & 0.86 & -0.87 & -0.49 & -0.20 & 0.24 & 4.55 \\
amihud & 73820 & 0.00 & 0.01 & 0.00 & 0.00 & 0.00 & 0.00 & 0.05 \\
aa & 75271 & 4003.01 & 45731.98 & 0.00 & 3.00 & 15.00 & 56.00 & 2836238.00 \\
n.address & 74282 & 2759909.71 & 30798087.56 & 2.00 & 7697.25 & 17060.50 & 39343.75 & 731868972.00 \\
0-balance address & 74282 & 2547094.98 & 29087813.30 & 0.00 & 2547.00 & 6510.00 & 15932.00 & 700014066.00 \\
tx & 75138 & 12566.92 & 204164.91 & 0.00 & 2.00 & 14.00 & 67.00 & 8476219.00 \\
tv (in 1000\$) & 75003 & 4318.32 & 29512.60 & 0.00 & 0.02 & 4.66 & 87.44 & 269060.57 \\
txnv & 75138 & 0.00 & 0.00 & 0.00 & 0.00 & 0.00 & 0.00 & 0.00 \\
txnv30 & 73061 & 0.00 & 0.00 & 0.00 & 0.00 & 0.00 & 0.00 & 0.00 \\
tvnv & 75003 & 0.02 & 0.05 & 0.00 & 0.00 & 0.00 & 0.01 & 0.40 \\
tvnv30 & 72926 & 0.02 & 0.09 & 0.00 & 0.00 & 0.00 & 0.01 & 0.77 \\
aanv & 75271 & 0.00 & 0.00 & 0.00 & 0.00 & 0.00 & 0.00 & 0.00 \\
aanv30 & 73190 & 0.00 & 0.00 & 0.00 & 0.00 & 0.00 & 0.00 & 0.00 \\
\hline
\end{tabular}




\section{Table A2 Correlation matrix}

Pearson (spearman) correlation coefficients on the lower (upper) triangular; 04-July-2017 to 06-October-2020, 170 weeks, 652 cryptoassets. Market beta is estimated from t-28 days until t, size is the natural logarithm of market cap at time t, idiosyncratic volatility (ivol) is the standard deviation of the residuals after estimating the CAPM from t-28 days until t, momentum is the cumulative return from t-90 days to $t$, amihud equals the average absolute weekly return divided by the USD trading volume in the portfolio formation week. The value anomalies include transaction volume in USD to network value (tvnv), number of transactions to network value (txnv), and active addresses to network value (aanv). For the three value anomalies, I provide the results using the moving average over the past 30 days (t-30 days) in the nominator All variables are winsorized at the $1 \%$ and $99 \%$ level.

\begin{tabular}{llllllllllll}
\hline & beta & size & ivol & mom & amihud & txnv & txnv30 & tvnv & tvnv30 & aanv & aanv30 \\
\hline beta & & 0.12 & -0.02 & -0.07 & -0.03 & 0.06 & 0.03 & 0.1 & 0.1 & 0.06 & 0.02 \\
size & 0.12 & & -0.45 & 0.19 & -0.68 & -0.04 & -0.32 & 0.38 & 0.28 & -0.14 & -0.44 \\
ivol & -0.05 & -0.4 & & 0.02 & 0.52 & 0.01 & 0.15 & -0.17 & -0.1 & 0.05 & 0.19 \\
mom & -0.02 & 0.18 & 0.1 & & -0.15 & -0.08 & -0.16 & 0.05 & -0.02 & -0.1 & -0.19 \\
amihud & -0.04 & -0.21 & 0.29 & -0.01 & & -0.04 & 0.09 & -0.35 & -0.31 & 0.04 & 0.19 \\
txnv & 0.01 & -0.11 & 0.07 & -0.05 & 0.01 & & 0.7 & 0.65 & 0.48 & 0.96 & 0.64 \\
txnv30 & 0.01 & -0.17 & 0.12 & -0.07 & 0.04 & 0.75 & & 0.36 & 0.5 & 0.69 & 0.95 \\
tvnv & 0.02 & 0.13 & 0.01 & 0.07 & -0.03 & 0.27 & 0.17 & & 0.73 & 0.58 & 0.26 \\
tvnv30 & 0.03 & 0.07 & 0.07 & 0.05 & -0.02 & 0.17 & 0.2 & 0.49 & & 0.42 & 0.4 \\
aanv & 0 & -0.19 & 0.1 & -0.07 & 0.03 & 0.85 & 0.63 & 0.26 & 0.18 & & 0.69 \\
aanv30 & -0.01 & -0.25 & 0.14 & -0.1 & 0.06 & 0.61 & 0.86 & 0.17 & 0.21 & 0.7 & \\
\hline
\end{tabular}




\section{Table A3 Transition matrix}

Transition matrix for average active addresses over the past 30 days to network value ratio (aanv30), txnv30, and tvnv30; 04-July-2017 to 06-October-2020, 171 weeks. At the end of each Tuesday (t), all cryptoassets are sorted into quintiles on the corresponding variable. The elements of the matrix show the probability of cryptoasset $i$, to end in a different quintile in $t+1$. The row element represents the quintile at time $t$, and the column element the quintile at $t+1$.

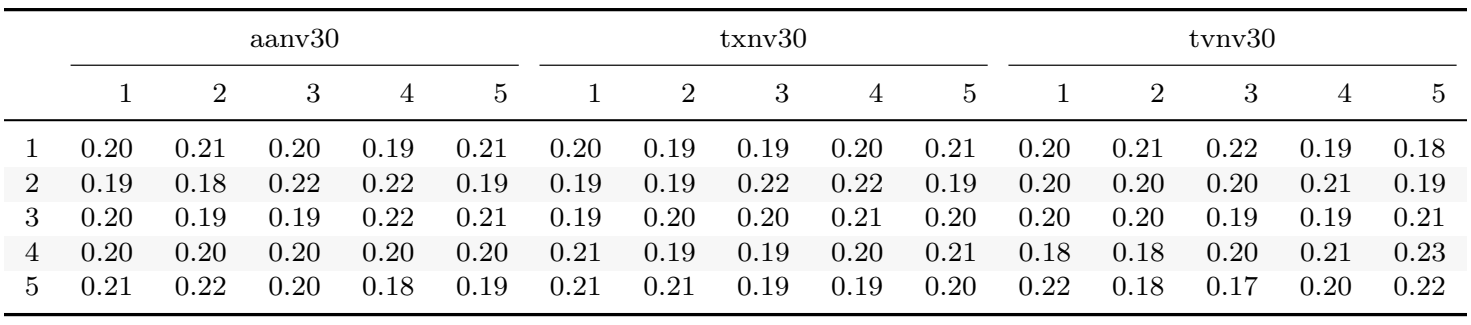




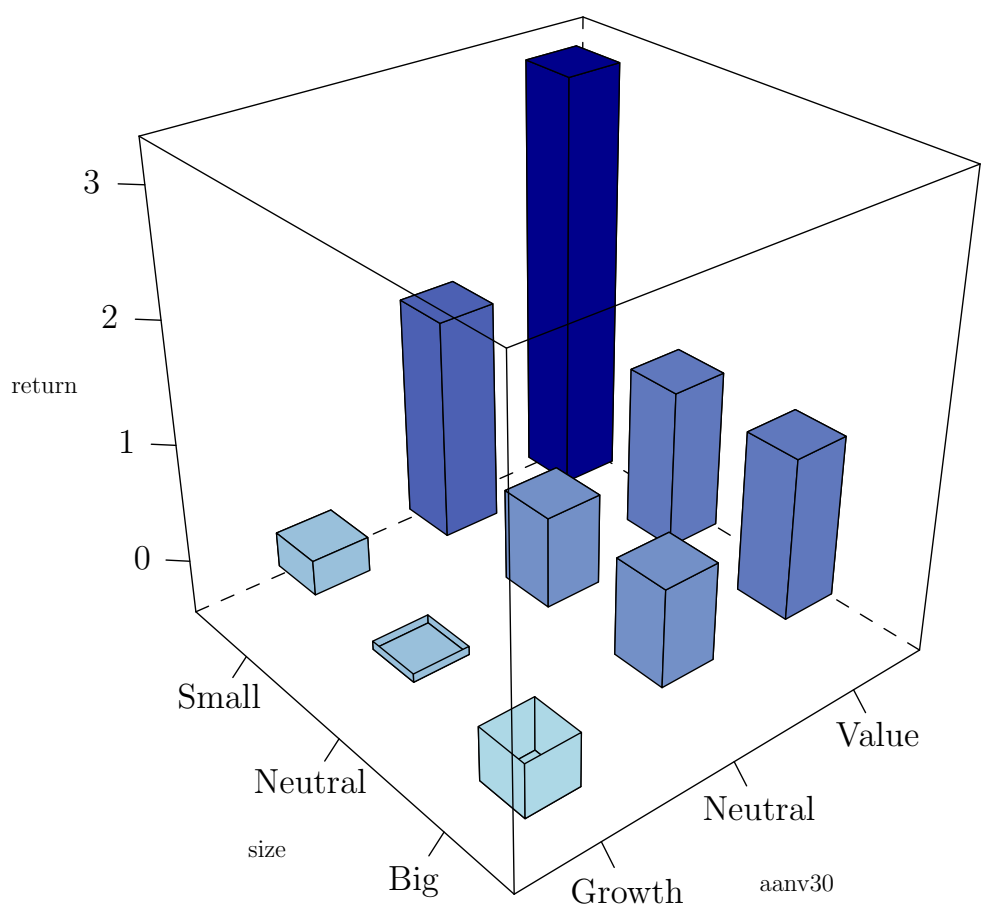

Figure A1. 3x3 independent size-aanv30 sort

Averages of weekly percent excess returns for value-weighted portfolios formed on size and average active addresses over the past 30 days to network value (aanv30); 04-July-2017 to 06-October-2020, 170 weeks. At the end of each Tuesday $(=\mathrm{t})$, cryptoassets are allocated independently into three size and three aanv30 groups. The intersection of the two sorts produces nine portfolios. Then, value-weighted returns are calculated from Tuesday ( $\mathrm{t}$ ) to Tuesday in the consecutive week $(\mathrm{t}+1)$. 


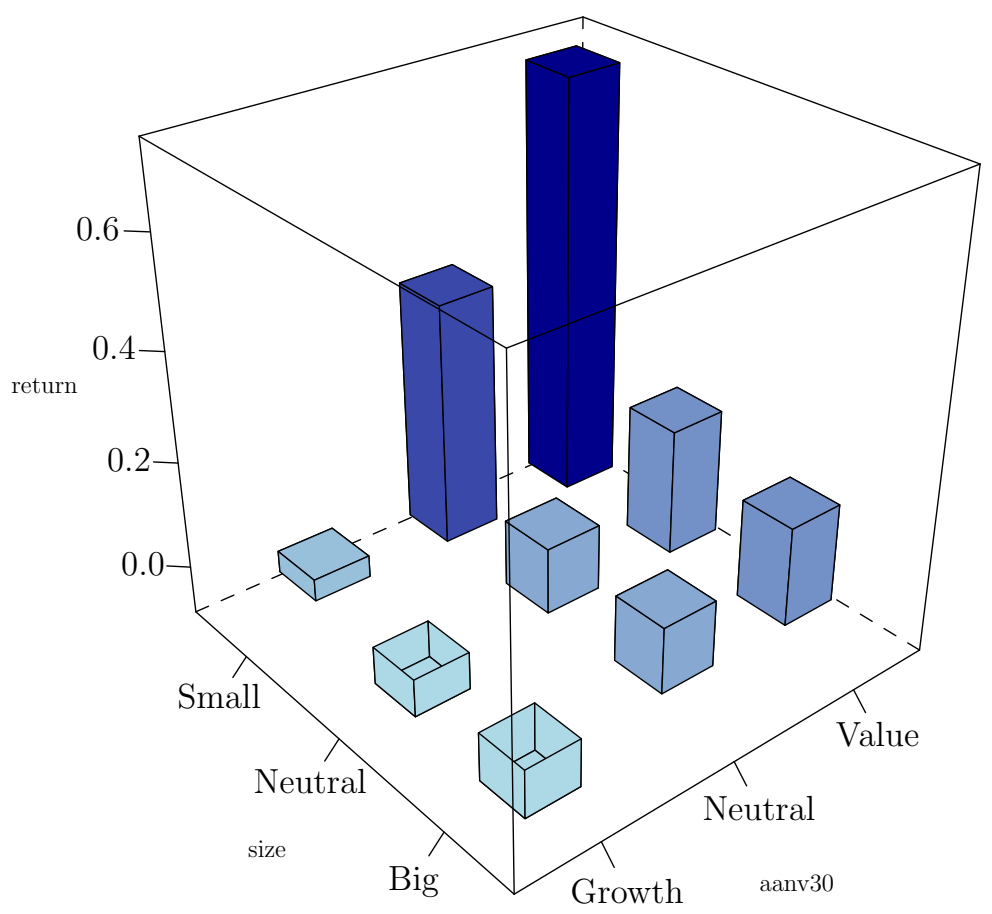

Figure A2. 3x3 independent daily sorts

Averages of daily percent excess returns for value-weighted portfolios formed on size and average active addresses over the past 30 days to network value (aanv30); 04-July-2017 to 06-October-2020, 170 weeks. At the end of each Tuesday $(=\mathrm{t})$, cryptoassets are allocated independently into three size and three aanv30 groups. The intersection of the two sorts produces nine portfolios. Then, value-weighted returns are calculated from Tuesday ( $\mathrm{t}$ ) to Tuesday in the consecutive week $(\mathrm{t}+1)$. 


\section{Table A4 Summary statistic of daily factor returns}

Summary statistics for daily factor percent returns; 04-July-2017 to 06-October-2020, 1190 days. At the end of each day, cryptoassets are assigned to $3 \times 3$ groups through unconditional sorts. In each group, the portfolio return is value-weighted. Panel A reports daily percent returns, standard deviation (Std. dev), and t-Statistic of the factor returns. Panel B shows the correlation for each set of factors. Panel $\mathrm{C}$ reports summary statistics of the components of the factors. $H M L_{s}$ is the average return on the portfolios of small value (high aanv30) cryptoassets minus the average return on the portfolios of small growth (low aanv30) cryptoassets. $H M L_{b}\left(H M L_{n}\right)$ is defined analogously for big (neutral) cryptoassets. $S M B_{g}$, $S M B_{n}, S M B_{v}, W M L_{s}, W M L_{n}$, and $W M L_{b}$ are defined in the same way. HML is the average of $H M L_{s}, H M L_{n}$, $H M L_{b}$.

\begin{tabular}{|c|c|c|c|c|c|c|c|c|c|c|}
\hline Panel A: & MKT & SMB & HML & WML & & Panel B: & MKT & SMB & HML & WML \\
\hline Mean & 0.131 & 0.344 & 0.427 & -0.89 & & MKT & 1 & -0.122 & 0.115 & -0.015 \\
\hline Std. dev & 0.04 & 0.024 & 0.022 & 0.025 & & SMB & -0.122 & 1 & -0.036 & -0.083 \\
\hline \multirow[t]{2}{*}{ t-Statistic } & 1.129 & 5.049 & 6.818 & -12.499 & & HML & 0.115 & -0.036 & 1 & 0 \\
\hline & & & & & & WML & -0.015 & -0.083 & 0 & 1 \\
\hline Panel C: & $H M L_{s}$ & $H M L_{n}$ & $H M L_{b}$ & $S M B_{g}$ & $S M B_{n}$ & $S M B_{v}$ & $W M L_{s}$ & $W M L_{n}$ & $W M L_{b}$ & \\
\hline Mean & 0.7 & 0.3 & 0.3 & 0.1 & 0.3 & 0.6 & -1.7 & -0.8 & -0.2 & \\
\hline Std. dev & 0.049 & 0.029 & 0.035 & 0.048 & 0.034 & 0.038 & 0.053 & 0.032 & 0.034 & \\
\hline t-Statistic & 4.998 & 3.585 & 2.713 & 0.986 & 3.264 & 5.147 & -11.211 & -8.455 & -1.754 & \\
\hline
\end{tabular}




\section{Table A5 Spanning regression daily}

Using three factors in regressions to explain average weekly returns of the fourth factor; 04-July-2017 to 06-October-2020, 1190 days. Model 1:

$$
M K T_{t}=\alpha_{t}+\beta_{1, t} S M B+\beta_{i, t} H M L+\beta_{3, t} W M L+\epsilon_{t}
$$

MKT is the value-weighted return minus the one-month Treasury bill rate; SMB (small minus big) is the size factor; HML (high minus low aanv30) is the value factor; WML is the momentum factor. T-statistics are reported in paranthesis below the coefficients. * **, *** indicate statistical significance levels at the $10 \%, 5 \%, 1 \%$ levels, respectively.

\begin{tabular}{lcccc}
\hline & \multicolumn{4}{c}{ Dependent variable: } \\
\cline { 2 - 5 } & MKT & SMB & HML & WML \\
& $(1)$ & $(2)$ & $(3)$ & $(4)$ \\
\hline MKT & & $-0.071^{* * *}$ & $0.061^{* * *}$ & -0.016 \\
& & $(-4.190)$ & $(3.857)$ & $(-0.884)$ \\
HML & $0.204^{* * *}$ & -0.024 & & 0.0001 \\
& $(3.857)$ & $(-0.779)$ & & $(0.004)$ \\
SMB & $-0.204^{* * *}$ & & -0.021 & $-0.090^{* * *}$ \\
& $(-4.190)$ & & $(-0.779)$ & $(-2.955)$ \\
WML & -0.041 & $-0.081^{* * *}$ & 0.0001 & \\
& $(-0.884)$ & $(-2.955)$ & $(0.004)$ & \\
Constant & & & \\
& 0.001 & $0.003^{* * *}$ & $0.004^{* * *}$ & $-0.009^{* * *}$ \\
& $(0.617)$ & $(3.995)$ & $(6.393)$ & $(-11.700)$ \\
\hline Observations & & & & \\
$\mathrm{R}^{2}$ & 1,190 & 1,190 & 1,190 & 1,190 \\
Adjusted $\mathrm{R}^{2}$ & 0.028 & 0.023 & 0.014 & 0.008 \\
Residual Std. Error $(\mathrm{df}=1186)$ & 0.025 & 0.020 & 0.011 & 0.005 \\
F Statistic $(\mathrm{df}=3 ; 1186)$ & 0.039 & 0.023 & 0.022 & 0.024 \\
\hline Note: & $11.314^{* * *}$ & $9.172^{* * *}$ & $5.494^{* * *}$ & $3.006^{* *}$ \\
\hline
\end{tabular}




\section{REFERENCES}

Amihud, Yakov, 2002, Illiquidity and stock returns: Cross-section and time-series effects, Journal of Financial Markets 5, 31-56.

Ankenbrand, Thomas, and Denis Bieri, 2018, Assessment of cryptocurrencies as an asset class by their characteristics, Investment Management and Financial Innovations 15, 169-181.

Banz, Rolf W., 1981, The relationship between return and market value of common stocks, Journal of financial economics 9, 3-18.

Basu, S., 1977, Investment performance of common stocks in relation to their price-earnings ratios: a test of the efficient market hypothesis, The Journal of Finance 32, 663-682.

Basu, Sanjoy, 1983, The relationship between earnings' yield, market value and return for NYSE common stocks. Further evidence, Journal of Financial Economics 12, 129-156.

Bhambhwani, Siddharth, Stefanos Delikouras, and George M. Korniotis, 2019, Do Fundamentals Drive Cryptocurrency Prices?, Working paper, Hong Kong University of Science and Technology .

Biais, Bruno, Christophe Bisiere, Matthieu Bouvard, Catherine Casamatta, and Albert J. Menkveld, 2018, Equilibrium Bitcoin Pricing, Working paper, University of Toulouse .

Bianchi, Daniele, 2020, Cryptocurrencies as an asset class? An empirical assessment, Journal of Alternative Investments 23, 162-179.

Blandin, Apolline, Ann Sofie Cloots, Hatim Hussain, Michel Rauchs, Rasheed Saleuddin, Jason G Allen, Bryan Zheng Zhang, and Katherine Cloud, 2019, Global Cryptoasset Regulatory Landscape Study, SSRN Electronic Journal .

Campbell, John Y., and Robert J. Shiller, 1988, Stock Prices, Earnings, and Expected Dividends, The Journal of Finance 43, 661-676. 
Carhart, Mark M., 1997, On persistence in mutual fund performance, The Journal of Finance $52,57-82$.

Chainanalysis, 2019, Can On-chain Data Help Us Spot Fake Exchange Trading Volumes?

Chan, Stephen, Jeffrey Chu, Saralees Nadarajah, and Joerg Osterrieder, 2017, A Statistical Analysis of Cryptocurrencies, Journal of Risk and Financial Management 10, 12.

Cheah, Eng Tuck, and John Fry, 2015, Speculative bubbles in Bitcoin markets? An empirical investigation into the fundamental value of Bitcoin, Economics Letters 130, 32-36.

CoinMarketCap, 2020, Market Data \& Cryptoasset Rank -.

Cong, Lin William, Ye Li, and Neng Wang, 2020, Tokenomics: Dynamic Adoption and Valuation, Working paper, Cornell University .

Corbet, Shaen, Brian Lucey, Andrew Urquhart, and Larisa Yarovaya, 2019, Cryptocurrencies as a financial asset: A systematic analysis, International Review of Financial Analysis 62, $182-199$.

Corbet, Shaen, Brian Lucey, and Larisa Yarovaya, 2018, Datestamping the Bitcoin and Ethereum bubbles, Finance Research Letters .

Crypto Rating Council, 2020, Crypto Rating Council - Asset Ratings.

Dale, Richard S., Johnnie E. V. Johnson, and Leilei Tang, 2005, Financial markets can go mad: evidence of irrational behaviour during the South Sea Bubble, The Economic History Review 58, 233-271.

Erazo, Felipe, 2020, Someone Transferred a Billion Dollars in Bitcoin for Less Than $\$ 5$.

Fama, Eugene F., and Kenneth R. French, 1992, The Cross-Section of Expected Stock Returns, The Journal of Finance 47, 427-465. 
Fama, Eugene F., and Kenneth R. French, 1993, Common risk factors in the returns on stocks and bonds, Journal of Financial Economics 33, 3-56.

Fama, Eugene F., and Kenneth R. French, 2012, Size, value, and momentum in international stock returns, Journal of Financial Economics 105, 457-472.

Fama, Eugene F., and Kenneth R. French, 2015, A five-factor asset pricing model, Journal of Financial Economics 116, 1-22.

Fama, Eugene F., and Kenneth R. French, 2017, International tests of a five-factor asset pricing model, Journal of Financial Economics 123, 441-463.

Fama, Eugene F., and James D. MacBeth, 1973, Risk, Return, and Equilibrium: Empirical Tests, Journal of Political Economy 81, 607-636.

Fidelity Investments, 2020, Growing Number of Institutional Investors Believe That Digital Assets Should Be a Part of Their Investment Portfolios.

FINMA, 2018, FINMA publishes ICO guidelines.

Gibbons, Michael R., Stephen A. Ross, and Jay Shanken, 1989, A Test of the Efficiency of a Given Portfolio, Econometrica 57, 1121.

Gkillas, Konstantinos, and Paraskevi Katsiampa, 2018, An application of extreme value theory to cryptocurrencies, Economics Letters 164, 109-111.

Gregoriou, Andros, 2019, Cryptocurrencies and asset pricing, Applied Economics Letters 26, 995-998.

Griffin, John M., and Amin Shams, 2020, Is Bitcoin Really Untethered?, The Journal of Finance 75, 1913-1964.

Grobys, Klaus, and Niranjan Sapkota, 2019, Cryptocurrencies and momentum, Economics Letters 180, 6-10. 
Härdle, Wolfgang Karl, Campbell R. Harvey, and Raphael C.G. Reule, 2020, Understanding Cryptocurrencies, Journal of Financial Econometrics 18, 181-208.

Harvey, Campbell R, and Yan Liu, 2016, ... and the Cross-Section of Expected Returns, The Review of Financial Studies 29, 5-68.

Henderson, M. Todd, and Max Raskin, 2019, A Regulatory Classification of Digital Assets: Toward an Operational Howey Test for Cryptocurrencies, ICOs, and Other Digital Assets, Columbia Business Law Review 2019.

Holovatiuk, Olha, 2020, Cryptocurrencies as an asset class in portfolio optimisation, Central European Economic Journal 7, 33-55.

Hu, Albert S., Christine A. Parlour, and Uday Rajan, 2019, Cryptocurrencies: Stylized facts on a new investible instrument, Financial Management 48, 1049-1068.

Jegadeesh, Narasimhan, and Sheridan Titman, 1993, Returns to Buying Winners and Selling Losers: Implications for Stock Market Efficiency, The Journal of Finance 48, 65-91.

Jegadeesh, Narasimhan, and Sheridan Titman, 2001, Profitability of momentum strategies: An evaluation of alternative explanations, Journal of Finance 56, 699-720.

Kaiser, Lars, and Sebastian Stöckl, 2020, Cryptocurrencies: Herding and the transfer currency, Finance Research Letters 33, 101214.

Kozlowski, Steven E., Michael R. Puleo, and Jizhou Zhou, 2020, Cryptocurrency return reversals, Applied Economics Letters 00, 1-7.

Li, Jiasun, and Guanxi Yi, 2019, Toward a factor structure in crypto asset returns, Journal of Alternative Investments 21, 56-66.

Li, Yi, Wei Zhang, Xiong Xiong, and Pengfei Wang, 2020, Does size matter in the cryptocurrency market?, Applied Economics Letters 27, 1141-1149. 
Lintner, John, 1965, Security Prices, Risk, and Maximal Gains From Diversification, The Journal of Finance 20, 587.

Liu, Weiyi, Xuan Liang, and Guowei Cui, 2020, Common risk factors in the returns on cryptocurrencies, Economic Modelling 86, 299-305.

Liu, Yukun, and Aleh Tsyvinski, 2018, Risks and Returns of Cryptocurrency, Working Paper, Yale University.

Makarov, Igor, and Antoinette Schoar, 2020, Trading and arbitrage in cryptocurrency markets, Journal of Financial Economics 135, 293-319.

Miller, Merton H., and Franco Modigliani, 1961, Dividend policy, growth, and the valuation of shares, the Journal of Business 34, 411-433.

Narayanan, Arvind, Joseph Bonneau, Edward Felten, Andrew Miller, and Steven Goldfeder, 2016, Bitcoin and Cryptocurrency Technologies: A Comprehensive Introduction, Technical report.

Oyedele, Akin, 2017, Robert Shiller says bitcoin is the best example of a bubble.

Pagnotta, Emiliano, and Andrea Buraschi, 2018, An Equilibrium Valuation of Bitcoin and Decentralized Network Assets, Working paper, Imperial College Business School .

Phillip, Andrew, Jennifer Chan, and Shelton Peiris, 2019, On long memory effects in the volatility measure of Cryptocurrencies, Finance Research Letters 28, 95-100.

Sharpe, William F., 1964, Capital Asset Prices: A Theory of Market Equilibrium under Conditions of Risk, The Journal of Finance 19, 425-442.

Shen, Dehua, Andrew Urquhart, and Pengfei Wang, 2020, A three-factor pricing model for cryptocurrencies, Finance Research Letters 34, 101248. 
Sovbetov, Yhlas, 2018, Factors influencing cryptocurrency prices: Evidence from bitcoin, ethereum, dash, litcoin, and monero, Journal of Economics and Financial Analysis 2, 1-27.

U.S Securities and Exchange Commission, 2020, SEC Charges Ripple and Two Executives with Conducting \$1.3 Billion Unregistered Securities Offering.

Vent, Jesse, and Sebastian Stoeckl, 2019, crypto2: Cryptocurrency Market Data.

Wang, Sha, and Jean Philippe Vergne, 2017, Buzz Factor or Innovation Potential: What explains cryptocurrencies' returns?, PLoS ONE 12.

Weber, Beat, 2016, Bitcoin and the legitimacy crisis of money, Cambridge Journal of Economics 40, 17-41.

Woo, Willy, 2017, Is Bitcoin In A Bubble? Check The NVT Ratio.

Zhang, Wei, and Yi Li, 2020, Is idiosyncratic volatility priced in cryptocurrency markets?, Research in International Business and Finance 54, 101252. 
About the author: Luca Liebi is currently a Ph.D. candidate and research assistant at the School of Finance of the University of St.Gallen, Switzerland. His research interests are empirical asset pricing and risk management with a special focus on cryptoassets. 